\title{
Detecção da microdeleção 7q11.23 por MLPA® e estudo clínico dos pacientes com síndrome de Williams-Beuren
}

Tese apresentada à Faculdade de Medicina da Universidade de São Paulo para obtenção do título de Doutor em Ciências

Programa de Pediatria

Orientadora: Prof. Dra. Chong Ae Kim

(Versão corrigida. Resolução CoPGr 5890, de 20 de dezembro de 2010. A versão original está disponível na Biblioteca FMUSP)

São Paulo 
Dados Internacionais de Catalogação na Publicação (CIP) Preparada pela Biblioteca da

Faculdade de Medicina da Universidade de São Paulo

Creprodução autorizada pelo autor

Honjo, Rachel Sayuri

Detecção da microdeleção 7q11.23 por MLPAß e estudo clínico dos pacientes com síndrome de Williams-Beuren / Rachel Sayuri Honjo. -- São Paulo, 2012. Tese(doutorado)--Faculdade de Medicina da Universidade de São Paulo. Programa de Pediatria.

Orientadora: Chong Ae Kim.

Descritores: 1.Sindrome de Williams 2.Elastina 3.Estenose aórtica supravalvular 5.Biologia molecular 6.Multiplex Ligation-dependent Probe Amplification ${ }^{\circledR}$

USP/FM/DBD-126/12 
À minha família e amigos, que me incentivaram a buscar esta conquista. Ao meu pai, Léo, que partiu antes da concretização deste projeto e que deixou saudades em meu coração. À minha mãe, Rósa, e ao meu irmão, Guilherme, pelo incentivo, carinho e apoio nos momentos difíceis. Ao Henry, pelo carinho, compreensão, suporte e paciência... muita paciência! 


\section{Agradecimentos}

Aos pacientes e seus familiares, que aceitaram participar desse estudo e me ensinaram muito nesse tempo de convivência, tanto profissional como pessoalmente.

À Profa. Dra Chong Ae Kim, pelo carinho, paciência, orientações e suporte ao longo desses anos. Tenho consciência da sorte de tê-la encontrado em minha vida e agradeço por ter me recebido tão calorosamente na Unidade de Genética do Instituto da Criança.

À Dra. Débora Bertola e à Dra. Lilian Albano, pela amizade, ensinamentos e também por me receberem com tanto carinho na Unidade de Genética, onde pudemos cultivar nossa amizade.

À Roberta Lelis Dutra, pela amizade e suporte laboratorial fundamental nos experimentos de Biologia Molecular deste projeto.

À Juliana Mazzeu e à Fernanda Jehee, pelo auxílio e treinamento na técnica de estudo molecular deste projeto.

À Michele Moreira Nunes, que sempre que necessário, deu o suporte psicológico aos pacientes e seus familiares no ambulatório de síndrome de Williams-Beuren da Unidade de Genética do Instituto da Criança.

Aos Drs. Israel Gomy, Isabel Furquim, Samantha Kelmann, Flavia Piazzon, Camila Rebelo, Charles Marques Lourenço e Cristina Rodrigues, pela amizade e pela ajuda nos momentos em que mais precisei. 
À Associação Brasileira de Síndrome de Williams (ABSW) e à querida "Jô", sempre parceiros e oferecendo suporte inigualável aos pacientes e suas famílias.

À Mariza Yoshikawa, da biblioteca do Instituto da Criança, pela cortesia e suporte na busca de artigos e nas horas de estudo na biblioteca.

À Lucélia Rodrigues, do Instituto da Criança, pelo auxílio na formatação de figuras.

Ao Prof. Ulysses Doria Filho, pelo suporte nos cálculos estatísticos.

À Fundação de Amparo à Pesquisa do Estado de São Paulo, FAPESP, e à Coordenação de Aperfeiçoamento de Pessoal de Nível Superior, CAPES, pelo apoio a este projeto. 
Esta tese está de acordo com as seguintes normas, em vigor no momento desta publicação:

Referências: adaptado de International Committee of Medical Journals Editors (Vancouver).

Universidade de São Paulo. Faculdade de Medicina. Divisão de Biblioteca e Documentação. Guia de apresentação de dissertações, teses e monografias. Elaborado por Anneliese Carneiro da Cunha, Maria Julia de A. L. Freddi, Maria F. Crestana, Marinalva de Souza Aragão, Suely Campos Cardoso, Valéria Vilhena. 3a ed. São Paulo: Divisão de Biblioteca e Documentação; 2011.

Abreviaturas dos títulos dos periódicos de acordo com List of Journals Indexed in Index Medicus. 


\section{LISTA DE FIGURAS}

LISTA DE TABELAS

LISTA DE ABREVIATURAS

LISTA DE SÍMBOLOS

\section{LISTA DE SIGLAS}

\section{RESUMO}

\section{ABSTRACT}

1 INTRODUÇÃO

1.1. Aspectos históricos e epidemiologia da síndrome de Williams-Beuren.2

1.2. Características clínicas................................................................

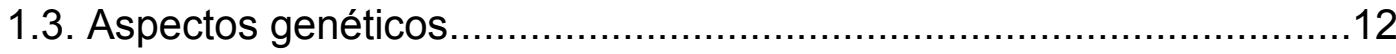

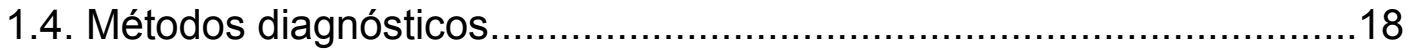

1.4.1. Hibridação in situ por fluorescência (FISH)...............................19

1.4.2. Marcadores polimórficos de DNA...............................................21

1.4.3. Hibridação genômica comparativa por array $(\mathrm{aCGH}) \ldots \ldots \ldots \ldots \ldots \ldots . . . . .23$

1.4.4. Multiplex Ligation-dependent Probe Amplification ${ }^{\circledR}\left(\mathrm{MLPA}^{\circledR}\right)$......24

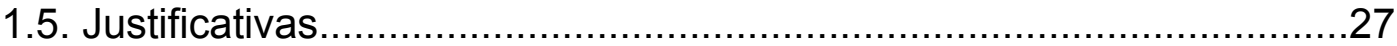

2 OBJETIVOS

3 MÉTODOS

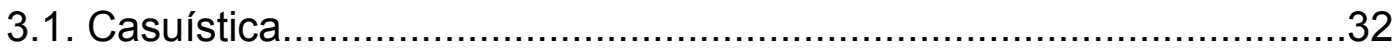

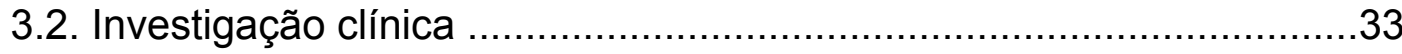


3.3. Estudo molecular por meio da técnica Multiplex Ligation-Dependent Probe Amplification ${ }^{\circledR}$ 34

3.3.1. Coleta de sangue e extração de DNA ..........................................35

3.3.2. Quantificação e diluição das amostras de DNA............................35

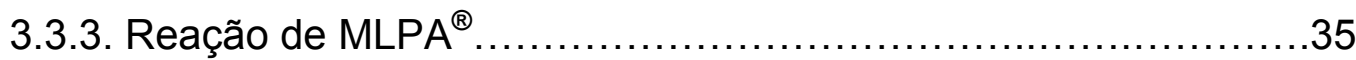

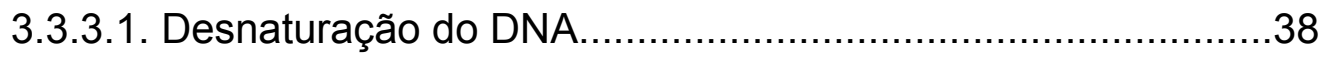

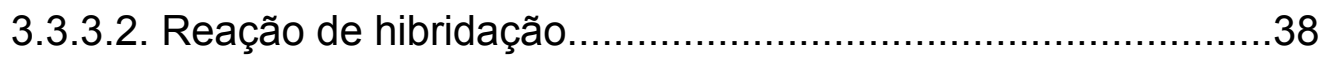

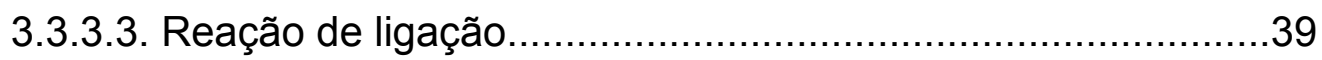

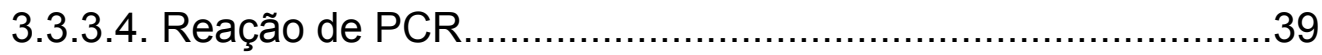

3.3.3.5. Separação dos fragmentos e análise dos resultados..............40

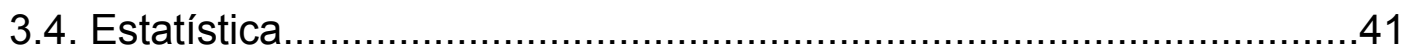

4 RESULTADOS

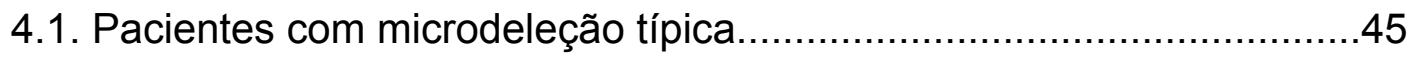

4.2. Paciente com microdeleção atípica................................................51

4.3. Pacientes sem microdeleção........................................................52

5 DISCUSSÃO

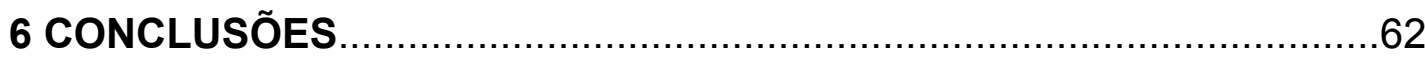

7 ANEXOS

ANEXO A - Folha de aprovação do estudo pela Comissão de Ética para Análise de Projetos de Pesquisa - CAPPesq da diretoria clínica do Hospital das Clínicas e da Faculdade de Medicina da Universidade de São Paulo................................................

ANEXO B - Termo de Consentimento Livre e Esclarecido..........................68

ANEXO C - Escore da síndrome de Williams-Beuren...............................71 
ANEXO D - Artigos submetidos ou publicados referentes a este projeto...72

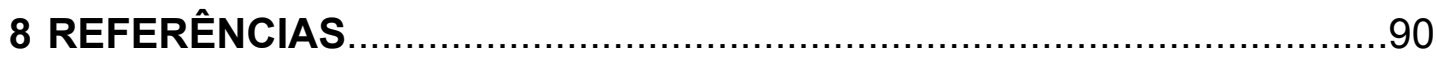




\section{LISTA DE FIGURAS}

Figura 1 - Visão gráfica da região deletada na SWB em 7q11.23..............15

Figura 2 - Genes na região $7 q 11.23$ envolvidos na SWB.........................17

Figura 3A - Teste de FISH negativo para a SWB................................20

Figura 3B - Teste de FISH positivo para a SWB...................................20

Figura 4 - Marcadores microssatélites em gel desnaturante.....................22

Figura 5 - Microdeleção da SWB com controle do mesmo sexo com técnica de hibridação genômica comparativa por array........................24

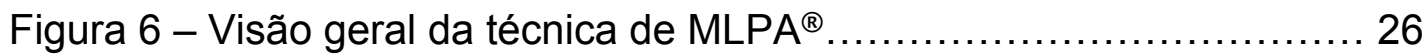

Figura 7 - Localização das sondas do kit P029 na região $7 q 11.23 \ldots \ldots \ldots \ldots . . . .37$

Figura 8 - Resultado de MLPA ${ }^{\circledR}$ negativo (normal)............................4

Figura 9 - Resultado de MLPA ${ }^{\circledR}$ positivo.............................................41

Figura 10 - Gêmeos com SWB, aos 11 anos........................................41

Figura 11 - Pacientes com microdeleção típica...................................47

Figura 12 - Pacientes com microdeleção típica......................................48

Figura 13 - Paciente com microdeleção atípica, aos 18 anos...................52

Figura 14 - Pacientes com MLPA ${ }^{\circledR}$ negativo (ausência de microdeleção)...53

Figura 15 - Pacientes com FISH negativo e MLPA ${ }^{\circledR}$ positivo para a SWB...61 


\section{LISTA DE TABELAS}

Tabela 1 - Sondas específicas para a região da SWB e sondas controle do kit P029 (MRC-Holland) .36

Tabela 2 - Características dos pacientes com microdeleção típica e sem microdeleção em 7q11.23 detectada por MLPA ${ }^{\circledR}$ .45 


\section{LISTA DE ABREVIATURAS}

$\begin{array}{ll}\text { Dr. } & \text { Doutor } \\ \text { Dra. } & \text { Doutora } \\ \text { Drs. } & \text { Doutores } \\ \text { et al. } & \text { e outros } \\ \text { Prof. } & \text { Professor } \\ \text { Profa. } & \text { Professora }\end{array}$




\section{LISTA DE SÍMBOLOS}

$\begin{array}{ll}\mathrm{Mb} & \text { megabase }(\mathrm{s}) \\ \mathrm{mL} & \text { mililitro } \\ \mathrm{n} & \text { número } \\ \mathrm{ng} / \mathrm{HL} & \text { nanograma por microlitro } \\ \mathrm{pb} & \text { pares de bases } \\ \mathrm{\mu L} & \text { microlitro } \\ { }^{\circ} \mathrm{C} & \text { graus Celsius } \\ < & \text { menor que }\end{array}$




\section{LISTA DE SIGLAS}

CAPPesq

Array $\mathrm{CGH}$

CAPES

DNPM

EASV

EDTA

FAPESP

FISH

FMUSP

HCFMUSP

LCR

MLPA $^{\circledR}$
Comissão de Ética para Análise de Projetos de Pesquisa do Hospital de Clínicas da Faculdade de Medicina da Universidade de São Paulo

hibridação genômica comparativa por array (Array Comparative Genomic Hybridization)

Coordenação de Aperfeiçoamento de Pessoal de Nível Superior

ácido desoxirribonucleico

desenvolvimento neuropsicomotor

estenose aórtica supravalvar

ácido etilenodiamino tetra-acético

Fundação de Amparo à Pesquisa do Estado de São

Paulo

hibridação in situ por fluorescencia (Fluorescence in situ hybridization)

Faculdade de Medicina da Universidade de São Paulo Hospital de Clínicas da Faculdade de Medicina da Universidade de São Paulo sequências de baixo número de cópias (low copy repeats)

Multiplex ligation-dependent probe amplification 
PCR

reação em cadeia da polimerase (polymerase chain reaction)

SVAS

supravalvular aortic stenosis

SWB

síndrome de Williams-Beuren

TSH

hormônio estimulante da tireoide

WBS

Williams-Beuren syndrome 


\section{RESUMO}

Honjo, RS. Detecção da microdeleção $7 q 11.23$ por MLPA® e estudo clínico dos pacientes com síndrome de Williams-Beuren [tese]. São Paulo: Faculdade de Medicina, Universidade de São Paulo; 2012.

INTRODUÇÃO: A síndrome de Williams-Beuren (SWB) é uma doença genética causada por uma microdeleção na região 7q11.23 e caracterizada por dismorfismos faciais típicos, deficiência intelectual, comportamento hipersociável, cardiopatia congênita, principalmente a estenose aórtica supravalvar (EASV), e outras malformações variáveis. MÉTODOS: Foram avaliados 65 pacientes (40 do sexo masculino, 25 do sexo feminino), com idades entre 2 e 59 anos (mediana $=14$ anos), com características clínicas sugestivas de SWB. Todos os pacientes eram filhos de pais normais. A técnica de Multiplex Ligation-dependent Probe Amplification ${ }^{\circledR}$ (MLPA $\left.{ }^{\circledR}\right)$ foi usada com kit específico com sondas da região da SWB (MRC Holland). As sondas foram hibridadas ao DNA e os fragmentos ligados foram amplificados por PCR e analisados com software específico. RESULTADOS: A deleção de todas as sondas da região $7 q 11.23$ testadas foi detectada por MLPA $\circledast$ em 55/65 pacientes. Um caso de deleção atípica, ou seja, menor que $1,5 \mathrm{Mb}$, foi observada em um paciente com quadro clínico parcial da síndrome. Os nove pacientes sem deleção tinham um diagnóstico clínico duvidoso da SWB. Dois pacientes tiveram MLPA ${ }^{\circledR}$ positivo para SWB embora apresentassem resultados de FISH negativos. Os achados clínicos dos pacientes com deleção típica foram: fácies típica $(98,2 \%)$, atraso do desenvolvimento neuropsicomotor $(98,2 \%)$, comportamento hipersociável $(94,5 \%)$, hiperacusia $(94,5 \%)$ e cardiopatia $(81,8 \%)$. Dentre os pacientes com cardiopatia, $42,2 \%$ apresentavam EASV (isolada ou associada a outras anomalias cardíacas), $26,7 \%$ apresentavam estenose pulmonar e $31,1 \%$ apresentavam outras cardiopatias isoladas ou em associação. Outros achados dos pacientes com deleção foram: anormalidades geniturinárias $(85,4 \%)$, escoliose $(56,4 \%)$, baixa estatura $(43,6 \%)$, hérnias inguinais e/ou umbilicais $(36,4 \%)$, hipertensão arterial $(36,4 \%$, com $20 \%$ destes apresentando estenose de artérias renais), estrabismo (34,5\%), microcefalia $(30,9 \%)$, sinostose radioulnar $(10,9 \%)$, hipotireoidismo $(14,5 \%)$ e hipotireoidismo subclínico (7,3\%). Hipercalcemia foi detectada em um paciente apenas. Outros dois pacientes apresentaram nefrocalcinose e um paciente apresentou hipercalciúria, com níveis de cálcio sérico normais. Três pacientes adolescentes foram a óbito por causas cardiovasculares, incluindo um caso de óbito após transplante cardíaco. CONCLUSÕES: A técnica de MLPA $\circledast$ foi eficaz na detecção da microdeleção na região $7 q 11.23$ possibilitando a confirmação diagnóstica da SWB em $84,6 \%$ dos pacientes estudados. Além disso, foi possível detectar uma deleção menor atípica em um paciente com fenótipo parcial e confirmar o diagnóstico em dois pacientes com quadro clínico típico de SWB e resultados de FISH negativos. 
Portanto, o MLPA $\AA$ constitui-se um método promissor na investigação diagnóstica da SWB. Por ser uma doença multissistêmica, a SWB exige cuidados multidisciplinares e acompanhamento específico a fim de se prevenir complicações.

Descritores: Síndrome de Williams, Elastina, Estenose aórtica supravalvular,

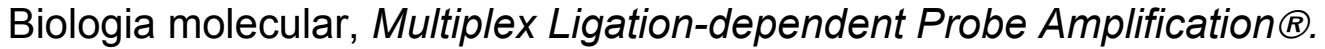




\begin{abstract}
Honjo, RS. Detection of the microdeletion $7 q 11.23$ by MLPA $\AA$ and clinical study of patients with Williams-Beuren syndrome [thesis]. São Paulo: Faculdade de Medicina, Universidade de São Paulo; 2012.
\end{abstract}

INTRODUCTION: Williams-Beuren syndrome (WBS) is a genetic disorder caused by a microdeletion in $7 q 11.23$ region. It is characterized by typical facial dysmorphisms, mental retardation, hipersociable behavior, congenital heart disease, mainly supravalvular aortic stenosis (SVAS), and other variable congenital malformations. METHODS: 65 patients (40 males, 25 females), aged 2-59 years old (median $=14$ years old), with clinical characteristics suggesting WBS, were evaluated. All patients had normal parents. Multiplex Ligation-dependent Probe Amplification ${ }^{\circledR}$ (MLPA $®$ ) was performed with a kit with probes in WBS region (MRC Holland). The probes were hybridized to the DNA and the ligated fragments were amplified by PCR and analyzed with specific software. RESULTS: The deletion for all tested probes in the $7 q 11.23$ region was detected by MLPA $\otimes$ in $55 / 65$ patients. One case of atypical deletion, smaller than $1.5 \mathrm{Mb}$, was observed in one patient with partial clinical picture of the syndrome. The nine patients without the deletion did not have a definitive clinical diagnosis of WBS. Two patients had positive MLPA $₫$ results even though they had negative FISH for WBS. The clinical characteristics of the patients with the typical deletion were: typical facies $(98.2 \%)$, neuropsicomotor delay $(98.2 \%)$, hypersociable behavior (94.5\%), hyperacusis (94.5\%) and congenital heart disease (81.8\%). Among the patients with cardiac abnormalities, $42.2 \%$ had SVAS (isolated or not), $26.7 \%$ had pulmonary valve stenosis and $31.1 \%$ had other cardiac anomalies (isolated or grouped). Other findings in patients with deletion comprised: genitourinary abnormalities $(85.4 \%)$, scoliosis $(56.4 \%)$, short stature $(43.6 \%)$, inguinal and/or umbilical hernias $(36.4 \%)$, arterial hypertension $(36.4 \%$, with $20 \%$ of these presenting renal arteries stenosis), strabismus $(34.5 \%)$, microcephaly $(30.9 \%)$, radioulnar synostosis $(10.9 \%)$, hypothyroidism (14.5\%), and subclinical hypothyroidism (7.3\%). Hypercalcaemia was detected in only one patient. Two other patients had nephrocalcinosis and one patient had hypercalciuria, with normal serum calcium levels. Three adolescents died due to cardiovascular problems, including one case that died after a cardiac transplantation. CONCLUSIONS: MLPA $®$ was effective to detect the microdeletion in $7 \mathrm{q} 11.23$ region confirming the diagnosis of WBS in $84.6 \%$ of the patients. It was also possible to detect a small atypical deletion in one patient with partial phenotype and confirm the diagnosis in two patients with typical clinical characteristics of WBS and negative FISH results. Thus, MLPA $\Theta$ is a promising method in the diagnostic investigation of WBS. WBS is a multisystemic disorder and therefore requires multidisciplinary care and specific follow-up in order to prevent complications. 
Descriptors: Williams Syndrome; Elastin; Aortic Stenosis, Supravalvular;

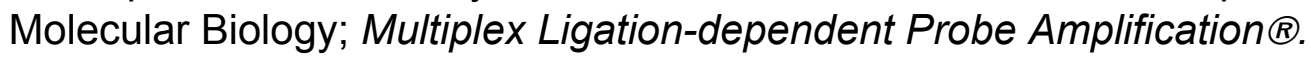


1 INTRODUÇÃO 


\section{INTRODUÇÃO}

\subsection{Aspectos históricos e epidemiologia da síndrome de Williams-} Beuren

A síndrome de Williams-Beuren (SWB), também conhecida como síndrome de Williams, é uma doença genética que foi descrita por Williams et al., em 1961, em quatro pacientes com estenose aórtica supravalvar (EASV), deficiência intelectual e características faciais peculiares, sugerindo representar uma nova síndrome. No ano seguinte, Beuren et al. (1962) descreveram mais pacientes com quadro clínico semelhante ao relatado por Williams et al., além de mencionarem um aspecto comportamental comum a esses pacientes - um comportamento "amigável”. Em 1963, Black e Carter chamaram a atenção da comunidade científica que os casos dismórficos descritos com EASV por Williams et al. e Beuren et al., em 1961 e 1962 respectivamente, assemelhavam-se muito no aspecto das características faciais de um outro grupo de pacientes, descritos inicialmente por Fanconi et al. em 1952 e Schlesinger et al. em 1956. Esses autores haviam descrito o quadro de crianças com hipercalcemia, baixa estatura e malformações congênitas variáveis, incluindo dismorfismos faciais e sopro cardíaco em algumas. Em 1964, Beuren et al. (1964) reportaram 10 pacientes com EASV, características faciais similares, deficiência intelectual e 
malformações dentárias. Sete dos 10 pacientes apresentavam estenose pulmonar periférica bilateral.

Com o crescente reconhecimento de pacientes com as manifestações da síndrome e semelhanças faciais, o espectro fenotípico da SWB começou a ser delineado. Jones e Smith (1975) analisaram 19 pacientes e constataram que as características mais consistentes eram: déficit de crescimento, microcefalia leve, deficiência intelectual e dismorfismos faciais. Em 1990, Morris e Carey descreveram três "novos" sinais diagnósticos da SWB: pregas sacrais incomuns, nevus flammeus na região dorsal e limitação à supinação, o que pode ser explicado pelo achado de sinostose radioulnar em alguns pacientes (Bzduch et al., 1988; Charvat et al., 1991; Pankau et al., 1993). Ao longo dos anos, os pacientes com SWB podem desenvolver uma postura com ombros caídos, lordose lombar acentuada, (Donnai e Karmiloff-Smith, 2000) além de contraturas em outras articulações, como quadris, joelhos, cotovelos, quirodáctilos e punhos (Kaplan et al., 1989). Morris (2010) mais recentemente descreveu o fenótipo da SWB como sendo caracterizado por características faciais dismórficas, deficiência intelectual, arteriopatia relacionada à elastina, baixa estatura, anormalidades do tecido conjuntivo, hipercalcemia infantil e um perfil cognitivo e de personalidade próprios da síndrome.

O Comitê de Genética da Academia Americana de Pediatria apresentou em uma publicação em 2001 um escore com critérios clínicos para a SWB, o qual foi baseado em um estudo de 107 pacientes avaliados por um grupo de 
especialistas. Um escore maior ou igual a 3 indica a realização de exame confirmatório (American Academy of Pediatrics, 2001).

A incidência da SWB é estimada em 1:20.000 nascidos vivos (MeyerLindenberg et al., 2006); alguns autores referem uma prevalência de até 1:7.500 (Stromme et al., 2002).

\subsection{Características clínicas}

A SWB é caracterizada por:

- Achados craniofaciais típicos: fronte ampla, alargamento medial das sobrancelhas, um aspecto de edema periorbitário, estrabismo, ponte nasal achatada, hipoplasia malar, bochechas e lábios volumosos, filtro nasolabial longo e suavemente marcado (Dupont et al., 1970; Jones e Smith, 1975; Burn, 1986; Donnai e Karmiloff-Smith, 2000). Em muitos adultos cabelos grisalhos podem surgir precocemente (Donnai e Karmiloff-Smith, 2000) e a face vai se tornando mais alongada e menos típica com a idade (Burn, 1986).

- Anormalidades do crescimento: crescimento intrauterino restrito ocorre em $35 \%$ das meninas e $22 \%$ dos meninos, com crescimento pós-natal deficiente nos primeiros dois anos de vida (Pankau et al., 1992). A baixa estatura é uma característica comum da síndrome: 30 a $40 \%$ dos pacientes têm estatura abaixo do terceiro percentil das 
curvas de crescimento padrão (Francke, 1999). Nogueira et al. (2011) estudaram o crescimento de 17 pacientes brasileiros e concluíram que a baixa estatura é uma característica intrínseca da SWB e pode ser agravada nos primeiros anos de vida pelos problemas de alimentação. Há na literatura um caso de paciente com SWB e deficiência de hormônio do crescimento, com sucesso observado da terapia de substituição desse hormônio (Kuijpers et al., 1999). Partsch et al. (1999) observaram que ocorre um estirão puberal prematuro e abreviado em ambos os sexos, o que poderia contribuir para a baixa estatura final observada de 152,4 $\pm 5,7 \mathrm{~cm}$ em mulheres $(n=38$ pacientes) e 165,2 $\pm 10,9 \mathrm{~cm}$ em homens ( $\mathrm{n}=43$ pacientes).

- Alterações cardiovasculares: estão presentes em cerca de $75 \%$ dos pacientes com SWB (Burn, 1986; Donnai e Karmiloff-Smith, 2000). A EASV é a cardiopatia mais prevalente, presente em até $3 / 4$ dos casos (Vernant et al., 1980; Morris, 1993). Desses, cerca de 30\% costuma ser grave (Vernant et al., 1980). Muitos pacientes com SWB são submetidos à cirurgia de correção para EASV com sucesso (Actis Dato et al., 1997); entretanto, uma nova intervenção cirúrgica às vezes pode ser necessária para os casos de EASV residual (Kumada et al., 1998). Outras cardiopatias congênitas, além da EASV, são descritas em pacientes com SWB, de forma isolada ou combinadas: estenose de ramos da artéria pulmonar, coarctação da aorta, prolapso de valva mitral, valva aórtica bicúspide e anormalidades coronarianas (Williams e Azouz, 1984; Bernard et al., 1985; Hallidie- 
Smith e Karas, 1988; Zalzstein et al., 1991). Nem sempre as alterações cardiovasculares são congênitas, como a coarctação da aorta e a estenose de artérias renais, podendo ser observados aparecimento e/ou progressão com a idade (Ino et al., 1988). Hipertensão arterial pode ocorrer ainda na infância, até mesmo em lactentes de 1 mês de vida (Bouchireb et al., 2010) ou adolescência, com uma frequência observada de $50 \%$ dos pacientes (Del Campo et al., 2006). Estenose de artérias renais foi um achado descrito em $44 \%$ dos pacientes com SWB por Pankau et al. (1996) e, de fato, estenose vascular periférica pode ser uma das causas de hipertensão na SWB (Bayazit et al., 2007). Outras causas de hipertensão arterial na SWB seriam um aumento da rigidez arterial devido à doença vascular e aumento da atividade simpática (Wessel et al., 1997), porém nem todos os pacientes com SWB e hipertensão apresentam alteração vascular detectada, indicando que outros mecanismos podem estar envolvidos (Del Campo et al., 2006). Em contrapartida, outros autores defendem que a haploinsuficiência da elastina nos pacientes com SWB levaria a uma hipertrofia da parede das artérias causada por proliferação de células musculares e arranjo anormal das fibras elásticas na camada média. Esses fatores levariam então a uma redução paradoxal da rigidez arterial e também a estenose dessas artérias (Lacolley et al., 2002). Rein et al. (1993) estudaram aspectos vasculares em três crianças com SWB por meio de ultrassonografia intraluminal e observaram hipertrofia de média nas artérias 
pulmonares e sistêmicas, o que resultava em estreitamento luminal. Sadler et al. (1998) estudaram as carótidas de pacientes com SWB e constataram que as paredes dessas artérias eram mais espessas que as de um grupo controle. No grupo de pacientes com SWB, a espessura arterial não variou significativamente com o sexo, a idade ou a presença (ou ausência) de doença cardíaca ou hipertensiva. Também já foi descrito infarto miocárdico em uma criança de três anos com SWB, indicando que pode haver comprometimento coronariano precoce (Bonnet et al., 1997). Mais recentemente, Unuma et al. (2011) descreveram os achados histopatológicos encontrados na autópsia de uma paciente com SWB que foi a óbito aos 72 anos de idade. Ela não apresentava EASV, porém foi encontrada estenose segmentar em grandes artérias (cervical comum, ilíaca interna e celíaca) nos segmentos distais a suas bifurcações, além de espessamento da média devido a proliferação de células musculares lisas. Interessantemente, apesar da idade e da presença de diabetes, hipercolesterolemia e hipertensão leves, a paciente apresentava ateromas mínimos em carótida e aorta. Morte súbita é uma das complicações descritas na SWB (Conway et al., 1990; Kececioglu et al., 1993; Bird et al., 1996; Suarez-Mier e Morentin, 1999; Wessel et al., 2004). Alguns casos de autópsia revelaram estenose de artérias coronárias e obstrução grave biventricular e, portanto, os mecanismos envolveriam isquemia miocárdica, diminuição do débito cardíaco e arritmias (Bird et al., 
1996). Outros pacientes foram a óbito após procedimentos anestésicos (Gupta et al., 2010). Uma hipótese seria a indução de síndrome de Kounis (disfunção coronariana alérgica) pela degranulação de mastócitos provocada pelo uso de certos agentes anestésicos (Kounis et al., 2010, 2011).

- Deficiência intelectual e perfil comportamental típico: atraso do desenvolvimento neuropsicomotor (DNPM) é frequente (American Academy of Pediatrics, 2001) e o coeficiente de inteligência dos pacientes afetados varia de 41 a 80 (Greer et al., 1997). Vários autores defendem a existência de um perfil cognitivo e comportamental próprio da síndrome, com dissociação entre os diferentes domínios, tais como um melhor desempenho de algumas habilidades de linguagem e déficit em relação às habilidades motoras e visuoespaciais (Udwin e Yule, 1991; Greer et al., 1997; Bellugi et al., 2000). Os pacientes apresentam um comportamento hipersociável, inclusive com estranhos (Gosch e Pankau, 1994; Doyle et al., 2004), porém com relacionamentos interpessoais muitas vezes inapropriados (Einfeld et al., 1997). Sintomas como ansiedade excessiva, fobias, sintomas obsessivos-compulsivos, comportamentos estereotipados, distúrbios do sono, déficit de atenção e hiperatividade podem ser encontrados desde a infância na SWB, podendo exigir terapia farmacológica (Udwin e Yule, 1991; Bawden et al., 1997; Einfeld et al., 1997; Power et al., 1997; Green et al., 2012). Com a idade, sintomas depressivos podem surgir em 
alguns pacientes (Einfeld et al., 1997), contrastando com a personalidade expansiva observada previamente na infância. Recentemente também surgiram relatos de presença de traços autísticos em alguns pacientes com SWB (Nunes, 2010; Nunes et al., 2011; Tordjman et al., 2012).

- Anormalidades cerebrais e cerebrovasculares: Algumas anormalidades cerebrais são descritas nos pacientes com SWB, porém não há ainda uma alteração que seja consistente em todos os pacientes ou que seja específica da síndrome. As anormalidades descritas incluem: diminuição do volume cerebral, com microcefalia, diminuição da substância branca e/ou cinzenta, cerebelo aumentado, malformação de Chiari tipo I e outras anormalidades em fossa posterior, alterações de corpo caloso, entre outras (Pober e Filiano, 1995; Perez Jurado et al., 1996; Mercuri et al., 1997; Reiss et al., 2000; Jones et al., 2002; Tomaiuolo et al., 2002). Também já foram descritos acidentes vasculares cerebrais isquêmicos em pacientes com SWB, devido a estenose de artérias cerebrais (Putman et al., 1995; Wollack et al., 1996; Lee et al., 2009).

- Anormalidades renais e geniturinárias: incluem malformações estruturais renais e vesicais, anormalidades vasculares (das artérias renais), nefrocalcinose e disfunção miccional (Stoermer et al., 1984; Biesecker et al., 1987; Pober et al., 1993; Pankau et al., 1996; Schulman et al., 1996). Dentre as anormalidades renais observadas encontram-se: rins assimétricos, agenesia ou hipoplasia renal, rim 
pélvico, nefrocalcinose e displasia cística (Biesecker et al., 1987; Pober et al., 1993; Pankau et al., 1996). Alguns pacientes, secundariamente a alguma alteração estrutural renal ou metabólica, podem apresentar disfunção renal (Biesecker et al., 1987; Pober et al., 1993). Divertículo vesical e hiperatividade detrusora podem ocorrer na SWB, podendo levar a alterações miccionais (Pankau et al., 1996; Schulman et al., 1996; Tobias-Machado et al., 1998; Sammour et al., 2006).

- Alterações oftalmológicas: a íris com padrão estrelado é uma característica marcante da SWB e pode auxiliar no diagnóstico (Holmstrom et al., 1990), assim como opacidades puntiformes no cristalino (Sugayama et al., 2002). Estrabismo, geralmente convergente, tortuosidade dos vasos retinianos, hipoplasia do nervo óptico e atrofia da aréola peripapilar também podem ser encontrados nesses pacientes (Greenberg and Lewis, 1988; Kapp et al., 1995; Sugayama et al., 2002).

- Anormalidades musculoesqueléticas: incluem hipermobilidade, luxações e contraturas articulares, limitação à supinação do antebraço com ou sem sinostose radioulnar, pregas sacrais incomuns, escoliose, cifose, lordose, hálux valgo e clinodactilia do quinto quirodáctilo (Kaplan et al., 1989; Charvat et al., 1991; Jones e Smith, 2006; Pober e Morris, 2007; Morris et al., 2010). Um estudo correlacionou uma maior incidência de escoliose e luxações articulares em pacientes com SWB e ao mesmo tempo heterozigotos 
para a deficiência de alfa-1-antitripsina, que causaria uma disfunção da elastase (Morris et al., 2010).

- Anormalidades endocrinológicas: são descritos hipercalcemia idiopática, hipercalciúria, hipotireoidismo e puberdade precoce (Udwin, 1990; Morris, 1993; Cherniske et al., 1999; Selicorni et al., 2006). Em adultos, observa-se prevalência aumentada de hipotireoidismo subclínico, anormalidades nos testes de tolerância à glicose e diabetes mellitus (Pober e Morris, 2007). Como previamente descrito, há na literatura um paciente com deficiência de hormônio do crescimento, tratado com sucesso (Kuijpers et al., 1999).

- Alterações auditivas: a hiperacusia é relatada em até $95 \%$ dos pacientes com SWB, geralmente com audiometria sem alterações (Martin et al., 1984; Klein et al., 1990; Nigam e Samuel, 1994; Donnai e Karmiloff-Smith, 2000; Blomberg et al., 2006). Alguns pacientes podem apresentar surdez neurossensorial progressiva (Johnson et al., 2001). A hiperacusia e a perda auditiva na SWB podem ter como base uma deficiência no reflexo acústico resultantes de disfunção do nervo auditivo (Gothelf et al., 2006). Alguns pacientes podem apresentar fixação ou fascinação por determinados sons, enquanto outros desenvolvem fonofobia a sons específicos (Levitin et al., 2005) ou àqueles que em sua infância eram causadores de desconforto auditivo (Davies et al., 1998). Muitos indivíduos com SWB apresentam uma musicalidade aflorada, que não fica somente no interesse em música, mas também conta com a presença de 
habilidades de ritmo, canto e capacidade inata de tocar instrumentos musicais (Levitin, 2005; Martínez-Castilla e Sotillo, 2008; MartínezCastilla et al., 2011).

- Outras manifestações: pode haver associação com doença celíaca (Chiaravalloti et al., 1995) e divertículo colônico (Pleatman e Dunbar, 1980), hérnias inguinais ou umbilicais (Jones e Smith, 2006); anormalidades dentárias, como dentes irregulares, espaçados e má oclusão (Axelsson et al., 2003; Axelsson, 2005).

\subsection{Aspectos genéticos}

A maioria dos casos de SWB é esporádica (Ewart et al., 1993; Perez Jurado et al., 1996; Antonell et al., 2006), ocasionada por deleções de novo com um risco de recorrência menor que 5\% (Cortada et al., 1980; Morris, 1993; Pankau et al., 2001). Alguns casos de transmissão vertical, ou seja, de genitor(a) para filho(a), foram reportados (Morris et al., 1993; Sadler et al., 1993; Ounap et al., 1998; Schubert, 2009).

A SWB é causada por uma microdeleção de 1-2 Mb no braço longo do cromossomo 7 (7q11.23), envolvendo uma região que abriga 28 genes (Schubert, 2009). A grande maioria dos pacientes com SWB (90\%) apresenta uma microdeleção de $1,55 \mathrm{Mb}$. Cerca de $8 \%$ dos pacientes apresenta uma microdeleção de 1,84 Mb. As microdeleções de 1,55 e 1,84 
Mb são consideradas as microdeleções "típicas" da SWB. As microdeleções maiores ou menores no mesmo intervalo podem ocorrer em $2 \%$ dos casos com quadros clínicos atípicos, muitas vezes correlacionados com o tamanho da microdeleção (Bayes et al., 2003). Os pacientes com microdeleções atípicas têm sido muito úteis para estudos de correlação clínico-molecular.

A microdeleção pode ser de origem materna ou paterna (Ewart et al., 1993; Dutly e Schinzel, 1996; Urban et al., 1996). Pesquisadores divergem quanto à significância da origem parental da microdeleção na SWB: enquanto uns não observaram diferenças fenotípicas entre os grupos com microdeleções maternas e paternas (Wu et al., 1998; Dutra, 2011), outros relacionaram microcefalia e atraso do crescimento mais marcante no grupo com microdeleções de origem materna (Perez Jurado et al., 1996).

Como atualmente é possível a identificação da origem parental do cromossomo 7 que abriga a microdeleção em pacientes com SWB, foi observado que o grupo de pais "transmissores" apresenta mais frequentemente uma microinversão de cerca de 1,5 a $1,9 \mathrm{Mb}$ na região cromossômica da SWB se comparados ao grupo "não-transmissor" (Osborne et al., 2001; Scherer et al., 2005). No caso de um genitor com esse polimorfismo, ou seja, uma microinversão na região da SWB, a chance de ter uma criança com SWB é estimada em cerca de 1:1.750, contrastando com o risco de 1:9.500 quando não há essa microinversão (Hobart et al., 2010). Em algumas famílias com recorrência da SWB em irmãos, filhos de pais fenotipicamente normais, foi encontrada essa microinversão que 
predispõe a recombinação alélica não homóloga e prole com microdeleção ou microduplicação da região (Scherer et al., 2005).

A SWB é considerada uma síndrome de genes contíguos pois, dependendo dos genes envolvidos na microdeleção, o fenótipo pode variar de EASV (que pode ser isolada ou associada a algumas manifestações, sem se caracterizar a SWB propriamente dita), até a expressão fenotípica completa da SWB, com as características clínicas e comportamentais típicas (Merla et al., 2002; Osborne et al., 2006).

A região da microdeleção da SWB em 7q11.23 é composta por uma região de cerca de 1,2 Mb contendo genes de cópia única, com três blocos ( $\mathrm{A}, \mathrm{B}$ e $\mathrm{C}$ ) contendo sequências de baixo número de cópias (LCR - low copy repeats). Cada bloco é composto por partes centroméricas, mediais e teloméricas (Figura 1). A recombinação homóloga não-alélica, que pode resultar na microdeleção (e microduplicação) da região 7q11.23, ocorre devido à alta similaridade desses blocos com sequências repetidas (Perez Jurado et al., 1996; Urban et al., 1996; Schubert, 2009). 


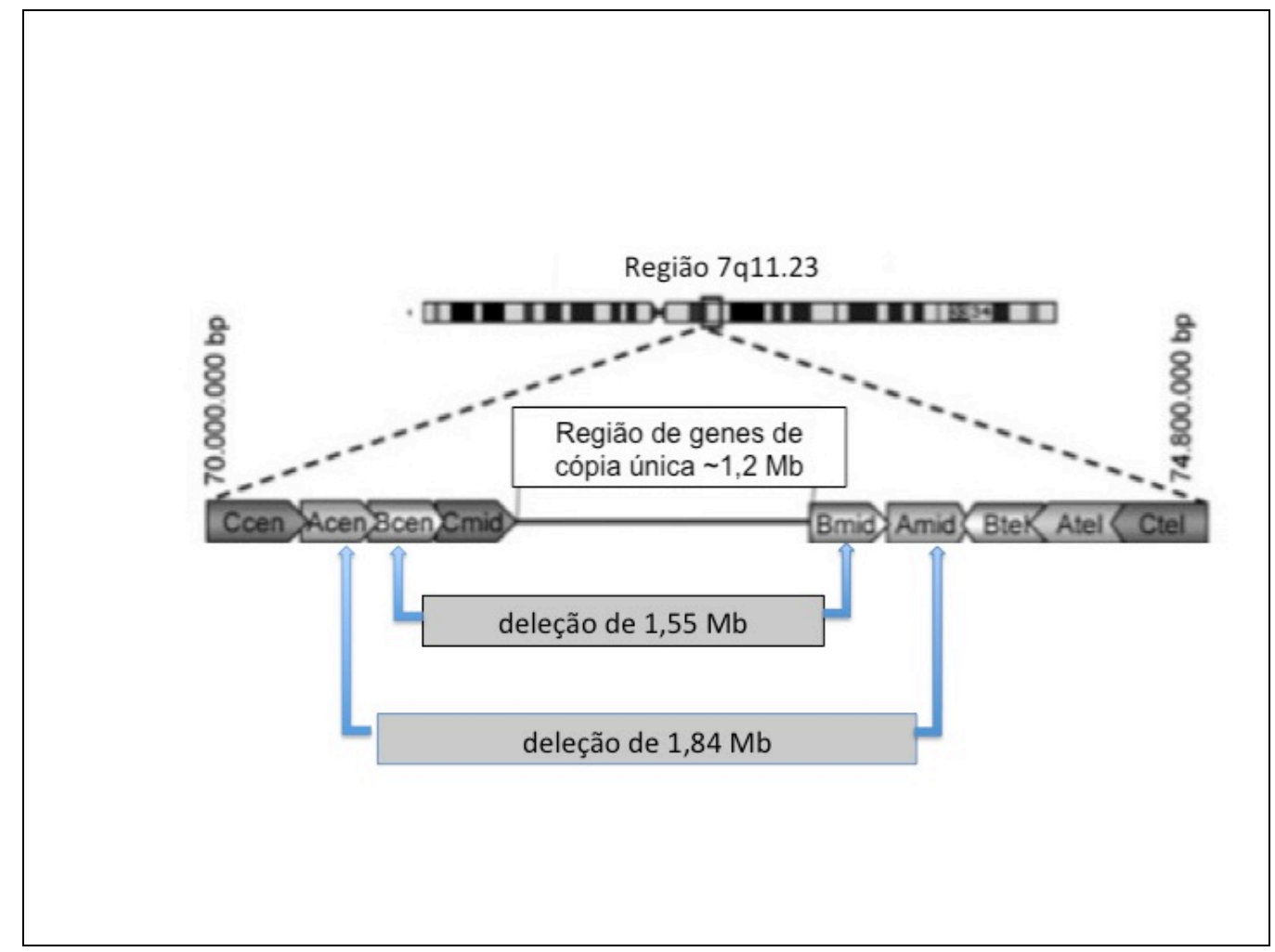

FONTE: Modificada de Schubert, 2009

Figura 1 - Visão gráfica da região deletada na SWB em 7q11.23. A localização e a orientação dos blocos com sequências de baixo número de cópias estão indicados pelas setas cinzas. Os pontos de quebra das microdeleções de 1,55 e 1,84 Mb estão indicados na parte inferior da figura pelas setas azuis

O bloco A consiste de quatro pseudogenes (STAG3, PMS2, GATS e fragmento de WBSCR19). STAG3 pode estar envolvido no pareamento cromossômico durante a meiose; PMS2 pode ter algum papel no reparo de DNA, tendo participação em algumas síndromes de câncer hereditário. Ainda não se sabe a exata função de GATS e WBSCR19 (Schubert, 2009). O bloco B contém os genes GTF2I, GTF2IRD2 e NCF1. Os genes GTF2l e GTF2IRD2 codificam fatores de transcrição e podem ter funções similares, no perfil cognitivo e comportamental da SWB, envolvendo o aspecto hipersociável do comportamento e os déficits visuoespacial e cognitivo 
(Hirota et al., 2003; Morris et al., 2003; Edelmann et al., 2007; Schubert, 2009). NCF1 codifica um componente da NADPH-oxidase, com importância no sistema imune, mas também com uma possível relação com hipertensão arterial na SWB (Del Campo et al., 2006; Schubert, 2009). O bloco C contém os genes POM121, NSUN5, TRIM50 e FKBP6 (Schubert, 2009). POM121 é parte de um complexo de poros nucleares que participam do transporte de macromoléculas. Em relação ao gene NSUN5, seu produto em humanos permanece incerto (Schubert, 2009). TRIM50 codifica uma E3 ubiquitina-ligase (Micale et al., 2008). FKBP6 faz parte do complexo sinaptonêmico, o qual está envolvido no pareamento meiótico e recombinação cromossômica; pode contribuir para algumas das manifestações da SWB, como hipercalcemia e atraso do crescimento (Meng et al., 1998; Schubert, 2009).

Entre os blocos C medial e B medial, existe uma região de genes de cópia única (Figura 2), com os seguintes genes identificados: FZD9, BAZ1B, BCL7B, TBL2, MLXIPL, VPS37D, DNAJC30, WBSCR22, STX1A, ABHD11, CLDN3, CLDN4, WBSCR27, WBSCR28, ELN, LIMK1, EIF4H, LAT2, RFC2, CLIP2, GTF2IRD1 e WBSCR23. O gene que codifica a elastina (ELN) é o mais estudado entre eles e sua hemizigosidade está implicada em anormalidades do tecido conjuntivo, arteriopatia com estenoses vasculares, incluindo a EASV, e aspectos dismorfológicos da face na SBW (Curran et al., 1993; Morris et al., 1993; Schubert, 2009; Pober, 2010). Dentre esses genes de cópia única, além do gene da elastina, alguns outros já têm sua função estudada em modelos animais ou estimada por meio de estudos de 
pacientes com microdeleções atípicas, porém ainda aguardam estudos mais aprofundados no futuro para terem seus papeis na SWB definitivamente esclarecidos. FZD9 tem sido relacionado a osteopenia; $B A Z 1 B$, a hipercalcemia e malformações cardíacas; STX1A, a alteração da tolerância a glicose; LIMK1, a déficit visuoespacial; CLIP2, a déficit visuoespacial e habilidades motoras; família GTF2I, incluindo GTF2IRD1, a anormalidades craniofaciais e dentárias, atraso do crescimento, anormalidades do comportamento, deficiência intelectual, perfil cognitivo da SWB, diminuição da espessura da retina e alteração das respostas visuais. Os demais genes ainda não têm sua função definida ao certo até o presente momento (Schubert, 2009; Pober, 2010).

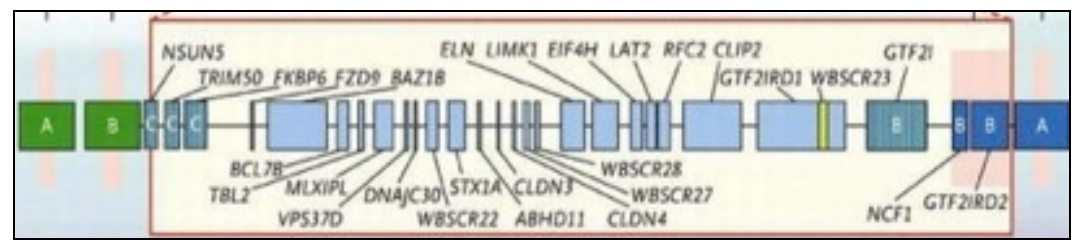

FONTE: Modificada de Pober, 2010

Figura 2 - Genes na região 7q11.23 envolvidos na SWB

Muitos estudos têm tentado estabelecer uma correlação genótipofenótipo na SWB, na tentativa de correlacionar o tamanho e os números de genes envolvidos na microdeleção com o espectro de manifestações clínicas dos pacientes (Wu et al., 1998; Tassabehji, 2003; Schubert, 2009). Entretanto, como mais de $90 \%$ dos pacientes apresenta um tamanho de microdeleção frequente mesmo apresentando diferenças de quadros 
clínicos, essa correlação tem se mostrado mais difícil do que inicialmente antecipada e aguardada. Por isso, pacientes com deleções parciais ou atípicas são de extrema importância. Há na literatura relatos de pacientes com fenótipos típicos ou parciais com deleções na região $7 q 11.23$ desde 0,1 Mb (Gagliardi et al., 2003; Morris et al., 2003; Schubert, 2009; Ferrero et al., 2010). Com o surgimento de novas técnicas de biologia molecular, um diagnóstico mais preciso e um delineamento acurado do tamanho das microdeleções, não somente na SWB, mas em outras síndromes de microdeleções, tornaram-se realidade.

\subsection{Métodos diagnósticos}

Embora os portadores da SWB apresentem um perfil fenotípico bastante característico, o diagnóstico de certeza só é possível com a realização de testes moleculares apropriados. A microdeleção na região 7q11.23 pode ser detectada por vários métodos, entre eles a hibridação in situ por fluorescência (FISH), marcardores polimórficos de DNA, hibridação genômica comparativa por array (CGH array) e Multiplex Ligation-dependent Probe Amplification ${ }^{\circledR}\left(\mathrm{MLPA}^{\circledR}\right)$. 


\subsubsection{Hibridação in situ por fluorescência (FISH)}

A citogenética clássica pelo bandamento $G$ (Giemsa) é muito útil para pesquisar alterações cromossômicas. Todavia, o nível de resolução desta técnica não possibilita a detecção da microdeleção em 7q11.23. A introdução das técnicas moleculares na citogenética clássica, como o método de hibridação in situ por fluorescência, conhecido simplesmente por FISH, solucionou este problema, pois permite a deteç̧ão de deleções inferiores a $5 \mathrm{Mb}$, as chamadas microdeleções. Vários pacientes com características clínicas da SWB começaram a ser diagnosticados com a microdeleção em 7q11.23 através do FISH (Borg et al., 1995; Lowery et al., 1995; Brewer et al., 1996; Sugayama, 2001; Sugayama et al., 2004).

A técnica de FISH é realizada em cultura de linfócitos obtida de sangue periférico. As células são estudadas em metáfase com a hibridação de sondas fluorescentes disponíveis comercialmente para a região da SWB e sonda controle para identificar o cromossomo 7. O material é analisado em fotomicroscópio de fluorescência para detectar a presença ou ausência dos sinais pareados em ambos cromossomos homólogos. Exemplos de metáfases estão ilustrados na Figuras 3A e 3B. Os pacientes com SWB tipicamente apresentarão um cromossomo com fluorescência positiva para a sonda controle e para a região da SWB e outro cromossomo com apenas um sinal, o da sonda controle (Figura 3B). A ausência de hibridação da 
sonda na região da SWB indica a microdeleção nesse cromossomo e confirma a SWB (Sugayama, 2001).
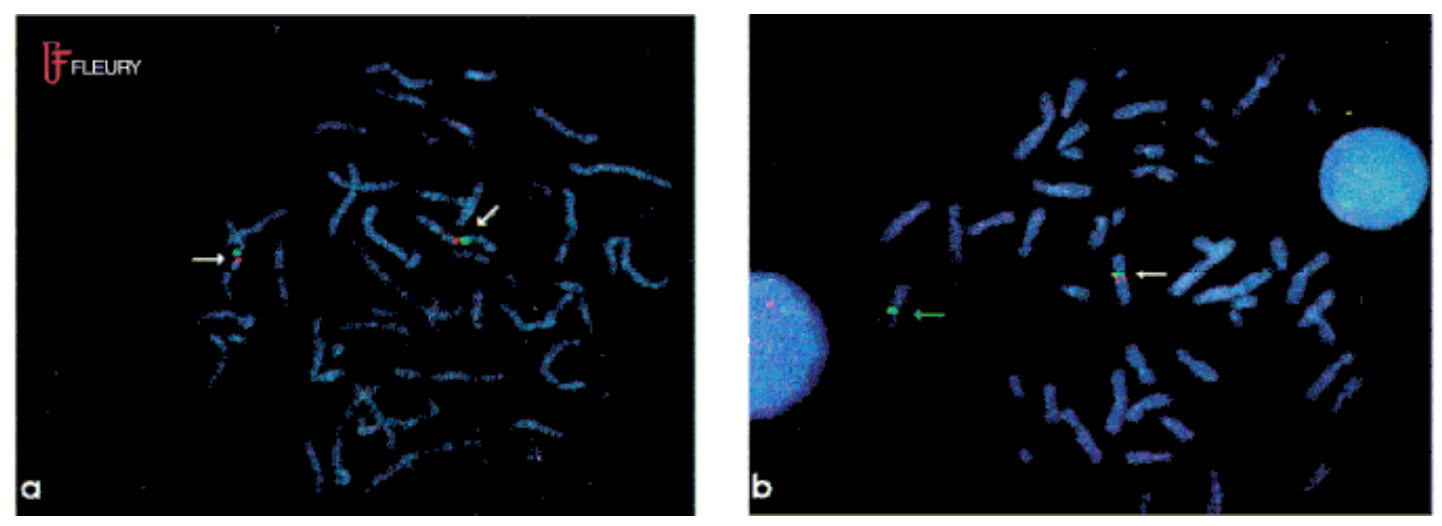

FONTE: Sugayama, 2001

Figura 3A - Teste de FISH negativo para a SWB. Há dois sinais verdes (sondas controle para o cromossomo 7) e dois sinais vermelhos (sondas para o gene da elastina, na região comumente deletada na SWB)

Figura 3B -Teste de FISH positivo para a SWB. Há somente um sinal vermelho (sonda para o gene da elastina)

Embora atualmente o FISH seja o método "padrão-ouro" para o diagnóstico da SWB, apresenta um custo elevado e ainda não está totalmente disponível em vários centros de referência públicos de Genética em nosso país. A positividade do FISH varia entre 91 e 100\% (Lowery et al., 1995; Nickerson et al., 1995; Brewer et al., 1996; Hirota et al., 1996), ou seja, alguns indivíduos, mesmo tendo quadro clínico sugestivo da SWB, podem ter resultado negativo pelo FISH. Atualmente, novas técnicas estão disponíveis para aprofundar a investigação molecular desses casos. 


\subsubsection{Marcadores polimórficos de DNA}

Uma outra forma de diagnóstico menos dispendiosa para a detecção das microdeleções é o uso de marcadores microssatélites polimórficos de DNA, que têm se tornado uma ferramenta importante no estudo de Genética Médica (Gilbert-Dussardier et al., 1995; Dutly and Schinzel, 1996; Urban et al., 1996; Dutra et al., 2011). Com essa técnica é possível definir a origem parental do cromossomo que abriga a microdeleção e mapear os pontos de quebra cromossômica. Por isso, o uso de marcadores pode ser útil na detecção de microdeleções atípicas e pequenas microdeleções, mas tem como pré-requisito a disponibilidade de material genético dos genitores (pais biológicos do paciente), o que nem sempre é possível.

Os marcadores microssatélites são sequências curtas repetitivas de DNA presentes em várias regiões do genoma e, como muitas vezes são polimórficas, variando em tamanho, ou número de repetições, podem ser característicos de cada indivíduo e altamente informativos na análise de doenças genéticas, comparando-se o probando com seus pais biológicos (Weber, 1990; Ellegren, 2004).

Para a técnica de marcadores polimórficos na SWB, primeiramente devem ser selecionados marcadores com grande índice de informatividade na região. Em estudo desenvolvido na Unidade de Genética do Instituto da Criança, Faculdade de Medicina da Universidade de São Paulo (FMUSP), Dutra et al. (2011) utilizaram cinco marcadores (D7S1870, D7S489, D7S613, 
D7S2476 e D7S489), com resultados conclusivos em todos os 97 pacientes investigados para SWB.

A genotipagem é realizada por reação em cadeia da polimerase (PCR) convencional e a análise é realizada por eletroforese em gel de poliacrilamida desnaturante. As bandas correspondentes ao paciente em investigação são comparadas às de seus genitores. A deleção é confirmada quando há falta de um dos alelos maternos ou paternos. O uso de vários marcadores é necessário pois muitas vezes não é possível diferenciar qual banda foi herdada de um ou outro genitor (resultado "inconclusivo" para aquele marcador) (Dutra, 2011). Exemplos de geis com as bandas podem ser vistos na Figura 4.

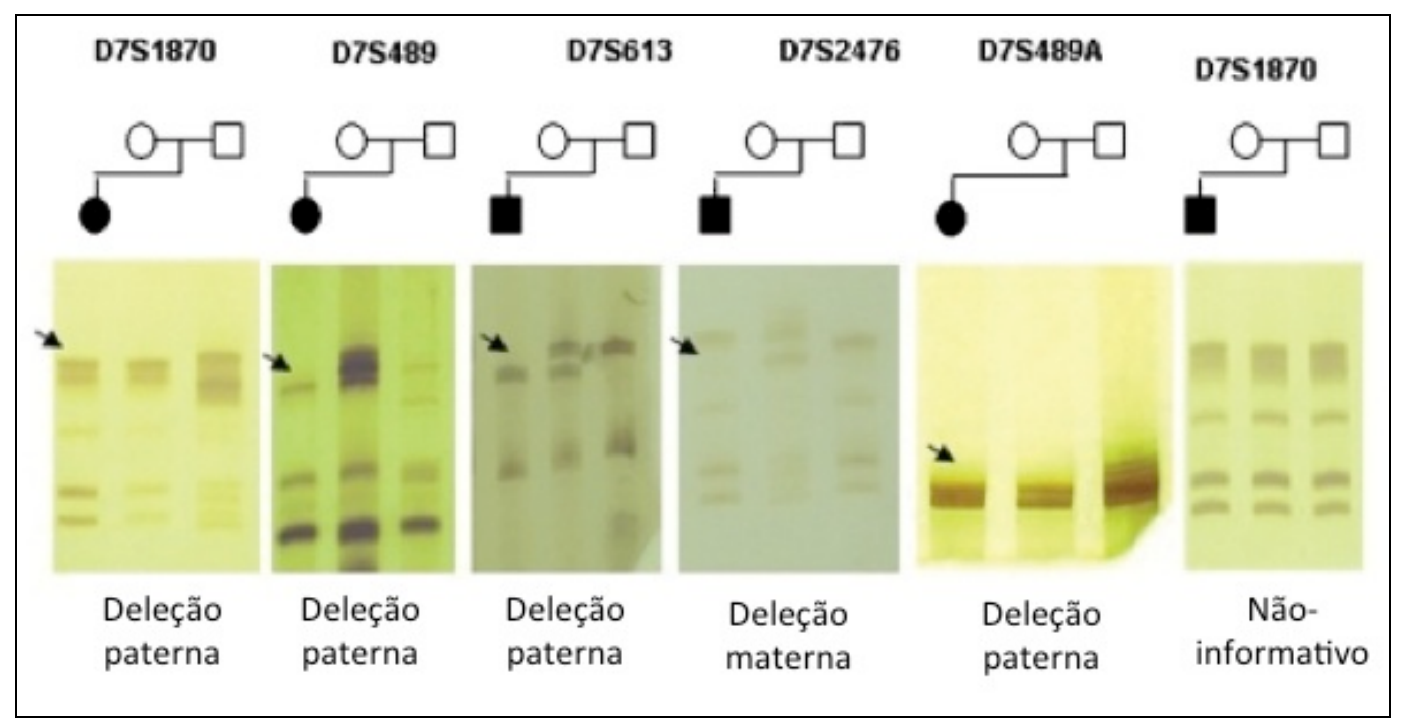

FONTE: Dutra et al., 2011

Figura 4 - Marcadores microssatélites em gel desnaturante. As colunas se referem ao DNA do paciente, mãe e pai, respectivamente. As setas indicam as perdas alélicas 


\subsubsection{Hibridação genômica comparativa por array (array CGH)}

Essa técnica, mais conhecida por sua sigla em inglês array $C G H$, foi desenvolvida no início dos anos 1990 e permite a identificação de segmentos cromossômicos com alterações em número de cópias. A amostra de DNA do paciente e outra amostra de referência, ou controle, são marcadas com diferentes fluorescências e hibridadas de modo competitivo a regiões cromossômicas alvo. O equilíbrio ou desequilíbrio entre as duas amostras pode ser observado pela diferença de intensidade de sinal (Lockwood et al., 2006). A microdeleção em 7q11.23 da SWB pode ser visualizada como um desequilíbrio nessa região, conforme ilustrado na Figura 5. Há na literatura alguns casos de SWB que puderam ser solucionados com o emprego da técnica de array CGH (Stankiewicz e Beaudet, 2007; Shah et al., 2008). 


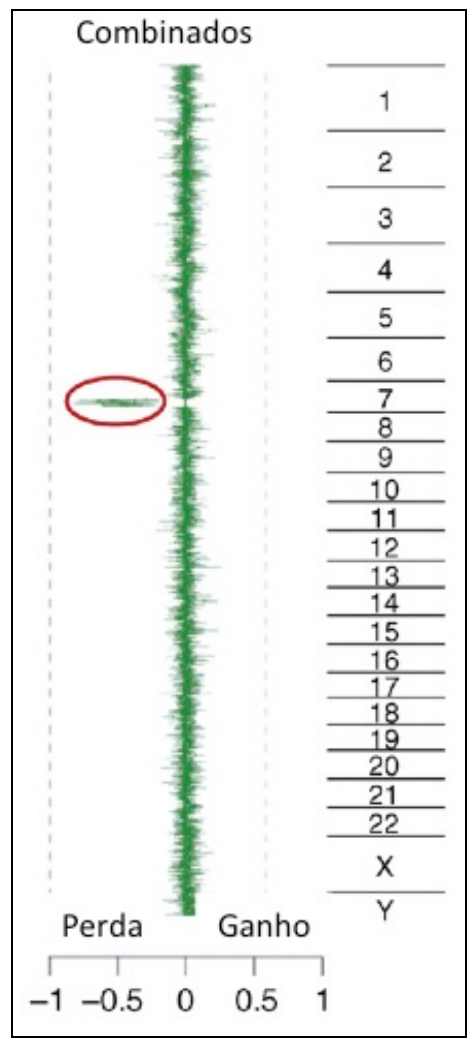

FONTE: Modificada de Stankiewicz e Beaudet, 2007

Figura 5 - Microdeleção da SWB com controle do mesmo sexo com técnica de hibridação genômica comparativa por array. Na coluna de dados combinados, as regiões onde há ganho de DNA possuem um sinal à direita e onde há perda / deleção o sinal fica à esquerda. Por isso, nesse caso, há indicação de perda de material correspondente à região 7q11.23 (círculo vermelho)

\subsubsection{Multiplex Ligation-dependent Probe Amplification ${ }^{\circledR}$ (MLPA $^{\circledR}$ )}

Em 2002 foi descrita a técnica de MLPA $^{\circledR}$ (Schouten et al., 2002), que consiste em um método relativamente fácil que permite a identificação de microdeleções e microduplicações de sequências-alvo específicas, com a 
hibridação simultânea e amplificação de mais de 40 sondas diferentes em uma única reação.

A técnica de $\mathrm{MLPA}^{\circledR}$ permite a identificação do número de cópias de uma dada sequência de DNA por meio da hibridação de sondas específicas (Figura 6). Essas sondas apresentam dois segmentos complementares às sequências-alvo de DNA: um oligonucleotídeo sintético curto e um oligonucleotídeo sintético longo derivado de fago M13. Este contém uma sequência stuffer que varia de tamanho nas diferentes sondas, permitindo a separação dos diferentes fragmentos por eletroforese capilar. Cada kit é composto por até 40 pares de sondas permitindo, assim, a análise de diversas regiões simultaneamente. Inicialmente o DNA é desnaturado, as sondas são hibridadas ao DNA e, em seguida, os fragmentos são ligados por uma ligase. Após uma nova desnaturação, os fragmentos formados pela junção das sondas são amplificados por PCR. A reação de PCR é realizada com um único par de primers, comum a todas as sondas. Em seguida, os fragmentos são submetidos à eletroforese capilar e os resultados são analisados com software específico (Schouten et al., 2002). 

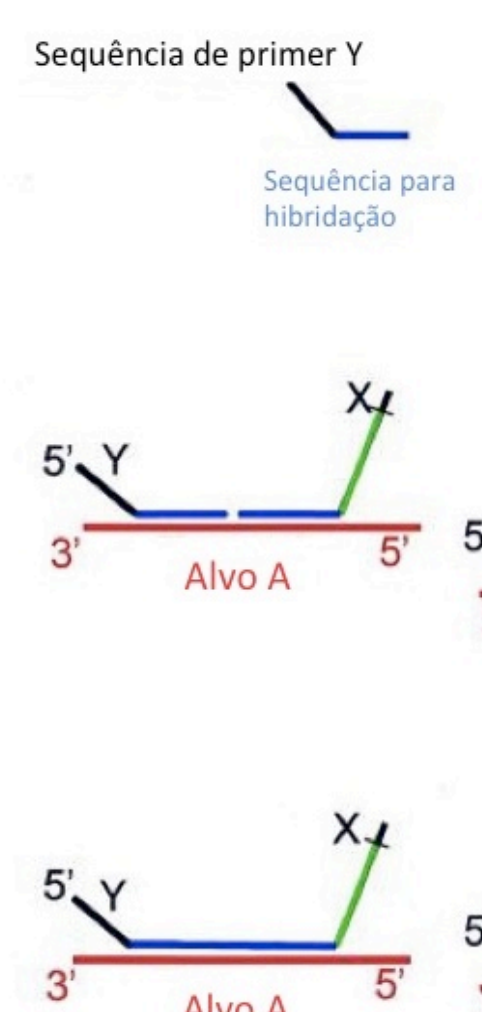

Alvo A
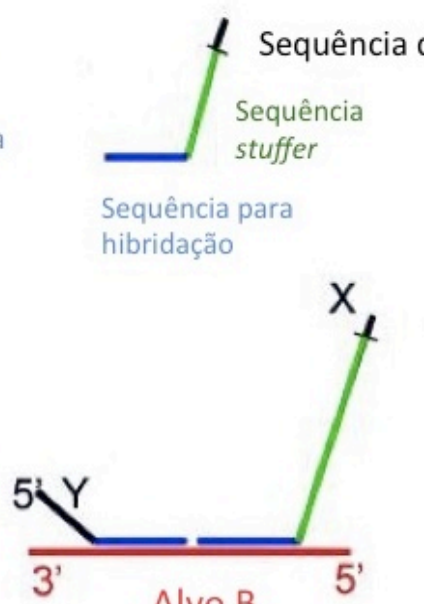

Alvo B
Cada oligonucleotídeo derivado de M13 contém uma sequência stuffer diferente.

As duas partes de cada sonda hibridam a sequências de DNA alvo adjacentes.

As duas partes das sondas hibridadas são ligadas por uma ligase termoestável.

Todos os produtos de ligação das sondas são amplificados por PCR utilizando-se somente um par de primers.

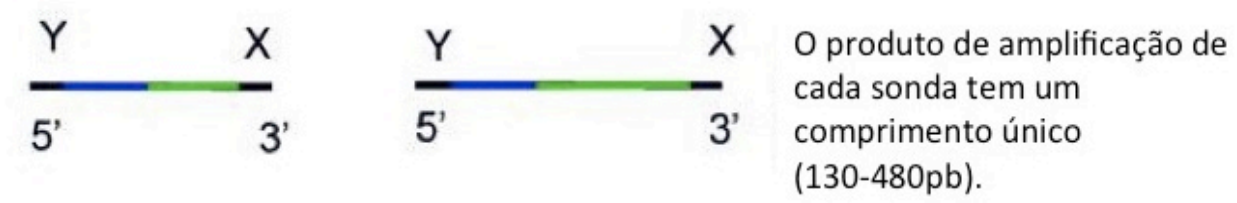

Os produtos amplificados são separados por eletroforese. As quantidades relativas de cada produto de amplificação refletem o número de cópias relativas das sequências-alvo.

FONTE: Modificada de Shouten et al., 2002

Figura 6 - Visão geral da técnica de MLPA ${ }^{\circledast}$

A técnica de $\operatorname{MLPA}^{\circledR}$ pode ser utilizada para a avaliação molecular de pacientes que apresentem características clínicas da SWB. A microdeleção em 7q11.23 pode ter um tamanho variável envolvendo o gene da elastina e outros adjacentes (Bayes et al., 2003). 
Alguns estudos têm demonstrado que o MLPA pode ser uma alternativa ao FISH no diagnóstico da SWB. Cho et al. (2009) encontrou resultados concordantes em quatro pacientes com SWB pesquisados por FISH e MLPA. Um grupo da Holanda estudou 63 pacientes com ambas técnicas. Em 53/63 a microdeleção foi detectada tanto por FISH como por MLPA. Os 10 pacientes restantes foram negativos pelos dois métodos. Contudo, em um paciente, no qual a microdeleção em $7 q 11.23$, que era pequena e atípica, não havia sido detectada por duas sondas comerciais de FISH, o MLPA conseguiu confirmar o diagnóstico (van Hagen et al., 2007).

Um maior detalhamento do MLPA ${ }^{\circledR}$ consta no capítulo "Métodos", pois foi a técnica utilizada no presente trabalho.

\subsection{Justificativas}

A SWB tem sido uma das principais linhas de pesquisa da Unidade de Genética do Instituto da Criança - FMUSP. Foram desenvolvidas duas teses de Doutorado, de Sugayama, em 2001, e Nunes, em 2010 ("Estudo genético-clínico e citogenética molecular pela técnica da hibridização in situ por fluorescência (FISH) em pacientes com síndrome de Williams-Beuren" e "Avaliação do funcionamento cognitivo de pacientes com Síndrome de Williams-Beuren", respectivamente) e duas dissertações de Mestrado, de Sbruzzi, em 2006, e Dutra, em 2011 (Estudo de marcadores polimórficos da 
região 7q11.23 para o diagnóstico da Síndrome de Williams-Beuren" e "Análise de marcadores moleculares para o diagnóstico da síndrome de Williams-Beuren", respectivamente).

Todos esses trabalhos foram desenvolvidos sob a orientação da Profa. Dra. Chong Ae Kim. O estudo de citogenética molecular de FISH foi realizado em parceria com o Laboratório Fleury e o de marcadores polimórficos no Laboratório de Biologia Molecular do InCor e LIM-36, no Instituto da Criança - FMUSP.

O presente estudo justifica-se pela formação de um centro de referência para a SWB, devido à experiência acumulada desde 2001, inclusive com o acompanhamento desses pacientes em ambulatório semanal específico, dedicado à síndrome, onde profissionais de várias áreas têm a oportunidade de conhecer pacientes de diferentes idades e fenótipos clínicos variáveis. O registro e a análise dos achados clínicos de um grande número de pacientes com a SWB podem auxiliar a padronizar medidas antecipatórias de seguimento clínico-laboratorial e contribuir para o aprofundamento do espectro de manifestações da SWB, bem como características importantes de sua história natural.

Em alguns pacientes com quadro clínico sugestivo de SWB o resultado do FISH pode ser negativo e outra técnica molecular, tal como o $\mathrm{MLPA}^{\circledR}$, poderia detectar a microdeleção para confirmação diagnóstica. 
2 OBJETIVOS 


\section{OBJETIVOS}

Os objetivos desse estudo compreenderam:

- Registrar e analisar os achados clínicos de pacientes com características da SWB;

- Delinear o espectro de manifestações da SWB, bem como características importantes de sua história natural;

- Pesquisar a microdeleção 7q11.23 por MLPA $^{\circledR}$ e analisar os dados clínicos dos pacientes com microdeleção. 
3 MÉTODOS 


\section{MÉTODOS}

\subsection{Casuística}

Tratou-se de um estudo retrospectivo e prospectivo, em que foram avaliados pacientes com suspeita clínica e alguns com confirmação molecular prévia da SWB (FISH ou marcadores polimórficos), em seguimento no Ambulatório de Genética do Instituto da Criança, Hospital das Clínicas da FMUSP. Pacientes novos, com suspeita de SWB, encaminhados do próprio Hospital das Clínicas ou de serviços externos, também foram convidados a participar.

O projeto, inscrito como Protocolo de Pesquisa $n^{\circ}$ 0111/08, assim como o Termo de Consentimento, foram aprovados pela Comissão de Ética para Análise de Projetos de Pesquisa - CAPPesq da Diretoria Clínica do Hospital das Clínicas e da Faculdade de Medicina da Universidade de São Paulo (Anexo A).

A participação no estudo estava condicionada à assinatura do Termo de Consentimento Livre e Esclarecido pelos pais ou responsáveis (Anexo B).

Foram convidados a participar do estudo 68 pacientes; entretanto, um já acompanhava em ambulatório de outro serviço de Genética e não houve interesse do responsável em participar desse estudo. Além disso, dois pacientes não compareceram à coleta de DNA e perderam seguimento no 
ambulatório. Portanto, na análise dos resultados foi incluído um total de 65 pacientes.

Os pacientes foram avaliados em uma consulta médica e uma ficha com o escore sugerido pelo Comitê de Genética da Academia Americana de Pediatria (2001) era preenchida (Anexo C). O critério de inclusão foi um escore igual ou maior que 3 e possibilidade de acompanhamento clínico na Unidade de Genética do Instituto da Criança. O critério para fácies típica foi o preenchimento dos critérios de características craniofaciais do referido escore, ou seja, mais que oito características.

\subsection{Investigação Clínica}

Todos os pacientes foram avaliados pela pesquisadora. Os dados clínicos e laboratoriais foram obtidos através de um protocolo que compreendeu:

- Anamnese;

- Exame físico completo do propósito com acompanhamento do crescimento e estadiamento puberal;

- Exame dismorfológico;

- Avaliação cardiovascular: avaliação clínica com ausculta cardíaca, medida da pressão arterial e ecocardiograma doppler (repetido a critério do cardiologista); 
- Avaliação do sistema urinário: parcial de urina, avaliação ultrassonográfica do aparelho urinário, dosagens de ureia e creatinina (anualmente);

- Determinação do nível de cálcio: concentração sérica de cálcio, relação cálcio/creatinina em uma amostra de urina (anualmente, ou a critério do nefrologista);

- Avaliação da função tireoideana: dosagem de TSH e T4 livre (anualmente ou mais frequentemente se houver sintomas sugestivos de alteração da tireoide);

- Avaliação oftalmológica;

- Encaminhamento a outras especialidades, conforme necessidade (por exemplo: Nefrologia, Cardiologia, Psiquiatria, Endocrinologia, etc.).

3.3. Estudo molecular por meio da técnica Multiplex LigationDependent Probe Amplification ${ }^{\circledR}$ (MLPA $^{\circledR}$ )

Os exames moleculares foram realizados no Laboratório de Investigação Médica - LIM 36 - do Instituto da Criança.

A técnica de MLPA $^{\circledR}$ foi realizada como descrito por Schouten et al. (2002). O protocolo de MLPA $^{\circledR}$ utilizado foi o recomendado pelo fabricante para o kit utilizado (MRC Holland), o qual está descrito a seguir. 


\subsubsection{Coleta de sangue e extração de DNA}

Os pacientes foram submetidos a punção de veia periférica, com a coleta de $5 \mathrm{~mL}$ de sangue em tubo com ácido etilenodiamino tetra-acético (EDTA). O sangue coletado foi encaminhado para extração de DNA genômico pela técnica de Salting-out (Miller et al., 1988).

\subsubsection{Quantificação e diluição das amostras de DNA}

A quantificação das amostras foi feita em eletroforese em gel de agarose $1,0 \%$, com corante de brometo de etídio e visualização em luz ultravioleta. Algumas amostras foram quantificadas por meio de espectrofotometria (NanoDrop $1000^{\circledR}$ ). As alíquotas de DNA foram armazenadas em refrigerador $\mathrm{a}-4^{\circ} \mathrm{C}$.

\subsubsection{Reação de MLPA}

Foi utilizado um kit (P029) com sondas específicas para os genes mapeados na região crítica da SWB: ELN, CLIP2 (CYLN2), LIMK1, TBL2, 
STX1A, RFC2, FZD9 e FKBP6, bem como sondas de outras regiões cromossômicas variadas, que funcionam como sondas-controle (Tabela 1 e Figura 7).

Tabela 1 - Sondas específicas para a região da SWB e sondas controle do kit P029 (MRC-Holland)

\begin{tabular}{|c|c|c|}
\hline Tamanho (nt) & Sonda & Posição cromossômica \\
\hline $64-70-76-82$ & $\begin{array}{c}\text { Sondas controle para quantidade } \\
\text { de DNA e desnaturação }\end{array}$ & \\
\hline 94 & Sonda controle sintética & $2 q 14$ \\
\hline 157 & Sonda controle 1112-L0549 & $3 q 12$ \\
\hline 166 & FKBP6 sonda 1629-L1215 & \\
\hline 175 & Sonda controle 1436-L0907 & $7 \mathrm{p} 15$, aprox. $42 \mathrm{Mb}$ da região da SWB \\
\hline 184 & Sonda controle 1217-L0694 & $4 q 34$ \\
\hline 193 & Sonda controle 1115-L0005 & $7 q 21$, aprox. $13 \mathrm{Mb}$ da região da SWB \\
\hline 202 & Sonda controle 1116-L0620 & $8 q 21$ \\
\hline 220 & Sonda controle 1119-L0559 & $10 q 22$ \\
\hline 229 & CLIP2 (CYLN2) sonda 1561-L1133 & \\
\hline 238 & Sonda controle 1165-L0721 & $7 \mathrm{p} 21$, aprox. $50 \mathrm{Mb}$ da região da SWB \\
\hline 247 & Sonda controle 1164-L0720 & $11 \mathrm{q} 13$ \\
\hline 256 & FZD9 sonda 1330-L0881 & \\
\hline 265 & Sonda controle 1181-L0742 & 7p22, aprox. $64 \mathrm{Mb}$ da região da SWB \\
\hline 274 & TBL2 sonda 1331-L0882 & \\
\hline 283 & Sonda controle 1326-L0873 & $17 \mathrm{p} 13$ \\
\hline 292 & STX1A sonda 1332-L0883 & \\
\hline 301 & Sonda controle 0971-L0558 & $10 q 21$ \\
\hline 310 & ELN sonda 1333-L0876 & \\
\hline 319 & Sonda controle 1231-L5816 & $22 q 11$ \\
\hline 328 & ELN sonda 1334-L0877 & \\
\hline 337 & Sonda controle 1310-L0848 & $5 q 35$ \\
\hline 346 & ELN sonda 1335-L0879 & \\
\hline 355 & Sonda controle 1045-L0615 & $8 q 22$ \\
\hline 364 & ELN sonda 1336-L0878 & \\
\hline 373 & Sonda controle 0968-L0555 & $9 q 21$ \\
\hline 382 & LIMK1 sonda 1337-L0880 & \\
\hline 391 & Sonda controle 1160-L0716 & $3 p 26$ \\
\hline 400 & RFC2 sonda 1658-L0240 & \\
\hline 409 & Sonda controle 0963-L0550 & $2 \mathrm{p} 14$ \\
\hline 418 & CLIP2 (CYLN2) sonda 1339-L0885 & \\
\hline 427 & Sonda controle 0680-L0121 & $7 q 35$, aprox. $74 \mathrm{Mb}$ da região da SWB \\
\hline 436 & Sonda controle 1057-L0630 & $17 \mathrm{p} 13$ \\
\hline 445 & Sonda controle 1440-L0909 & $2 p 16$ \\
\hline
\end{tabular}




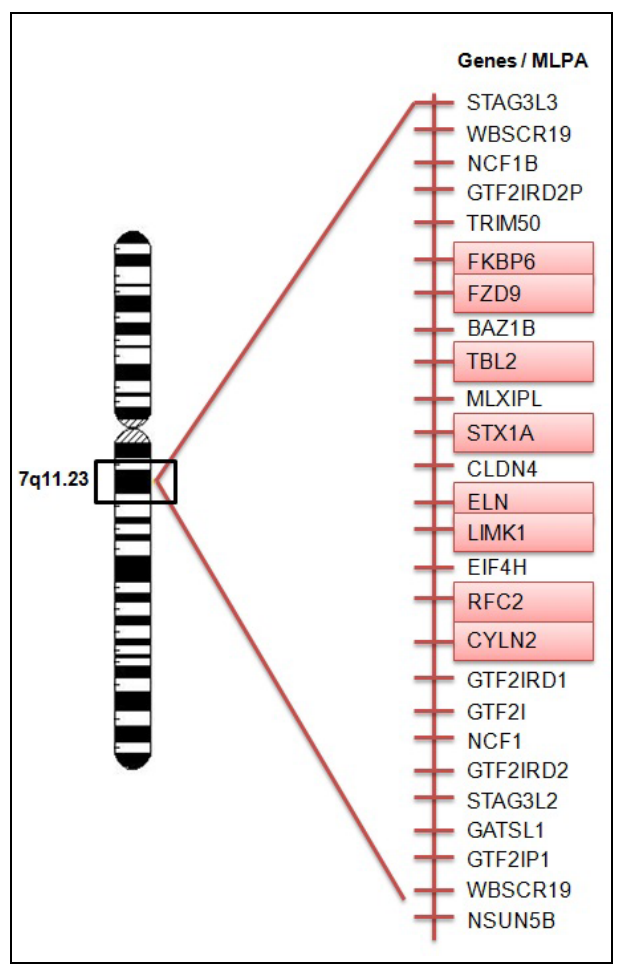

FONTE: Modificado de Dutra et al., 2012

Figura 7 - Localização das sondas do kit P029 na região 7q11.23

Para as reações de MLPA $^{\circledR}$ foi utilizado um termociclador com tampa aquecida, um controle "branco" (amostra sem DNA), um controle positivo de SWB (caso confirmado por FISH) e três controles normais, ou seja, sem SWB. 


\subsubsection{Desnaturação do DNA}

Em cada tubo de PCR de $0,2 \mathrm{~mL}$ foi adicionado $5 \mu \mathrm{L}$ de DNA (50 ng/ $\mu \mathrm{L})$ e colocado para desnaturar em $98{ }^{\circ} \mathrm{C}$ por 5 minutos, deixando resfriar a $25^{\circ} \mathrm{C}$ antes de abrir o termociclador.

\subsubsection{Reação de hibridação}

Uma solução de reagentes de hibridação era preparada: para cada amostra, adicionou-se 1,5 $\mu \mathrm{L}$ de buffer de MLPA e 1,5 $\mu \mathrm{L}$ da solução de sondas, misturando-se bem. Quando as amostras no termociclador atingiam $25{ }^{\circ} \mathrm{C}$, eram adicionados $3 \mu \mathrm{L}$ dessa solução preparada anteriormente em cada tubo e o conteúdo era bem misturado por pipetagens. Em seguida, as amostras eram incubadas por $95{ }^{\circ} \mathrm{C}$ por um minuto e deixadas a $60{ }^{\circ} \mathrm{C}$ por 16 horas. 


\subsubsection{Reação de ligação}

Uma solução de reagentes de ligação era preparada em gelo para esse passo contendo para cada amostra testada $3 \mu \mathrm{L}$ de ligase-65 buffer A, $3 \mu \mathrm{L}$ de ligase-65 buffer $\mathrm{B}, 25 \mu \mathrm{L}$ de água estéril e $1 \mu \mathrm{L}$ de ligase-65. No termociclador, a temperatura era pausada em $54{ }^{\circ} \mathrm{C}$ para a adição de $32 \mu \mathrm{L}$ da solução de reagentes de ligação em cada amostra, com leves pipetagens para a mistura às amostras. Prosseguia-se então para incubação por 15 minutos a $54{ }^{\circ} \mathrm{C}$, seguidos de 5 minutos a $98^{\circ} \mathrm{C}$ e pausa em $60{ }^{\circ} \mathrm{C}$.

\subsubsection{Reação de PCR}

Para esse passo, primeiramente eram adicionados em novos tubos 4 $\mu \mathrm{L}$ de SALSA PCR buffer, $26 \mu \mathrm{L}$ de água estéril e $10 \mu \mathrm{L}$ do produto de ligação do passo anterior (ligação). Uma solução de reagentes era preparada à parte, em gelo, contendo para cada tubo: $2 \mu \mathrm{L}$ de SALSA PCRprimers, $2 \mu \mathrm{L}$ de SALSA Enzyme dilution buffer, $5,5 \mu \mathrm{L}$ de água estéril e 0,5 $\mu \mathrm{L}$ de SALSA polimerase. No termociclador, pausado em $60{ }^{\circ} \mathrm{C}$, os novos tubos eram colocados e $10 \mu \mathrm{L}$ da solução contendo a polimerase eram adicionados em cada um deles. Após mistura por pipetagens, iniciava-se imediatamente a PCR, com a seguinte programação: 35 ciclos (30 segundos 
a $95^{\circ} \mathrm{C}, 30$ segundos a $60^{\circ} \mathrm{C}, 60$ segundos a $72{ }^{\circ} \mathrm{C}$ ). Ao final dos ciclos, os tubos ficavam incubados por 20 minutos a $72{ }^{\circ} \mathrm{C}$, seguidos por pausa em 15 ${ }^{\circ} \mathrm{C}$.

\subsubsection{Separação dos fragmentos e análise dos resultados}

A separação dos fragmentos foi realizada em sequenciador automático MegaBace ${ }^{\mathrm{TM}}$. A análise dos resultados foi realizada utilizando-se o software GeneMarker $^{\circledR}$ (SoftGenetics). Os padrões dos picos obtidos para as sondas específicas para a SWB contidas no kit foram comparados àqueles dos controles normais. Quando após a normalização a altura dos picos encontrava-se entre 0,75 e 1,25, os resultados eram considerados normais, ou seja, ausência da microdeleção em 7q11.23. Quando o pico era menor que 0,75 , o resultado era considerado positivo (presença de microdeleção). O software também demonstrava a relação dos picos de forma gráfica (Figuras 8 e 9) e em tabela, facilitando a interpretação dos resultados. 


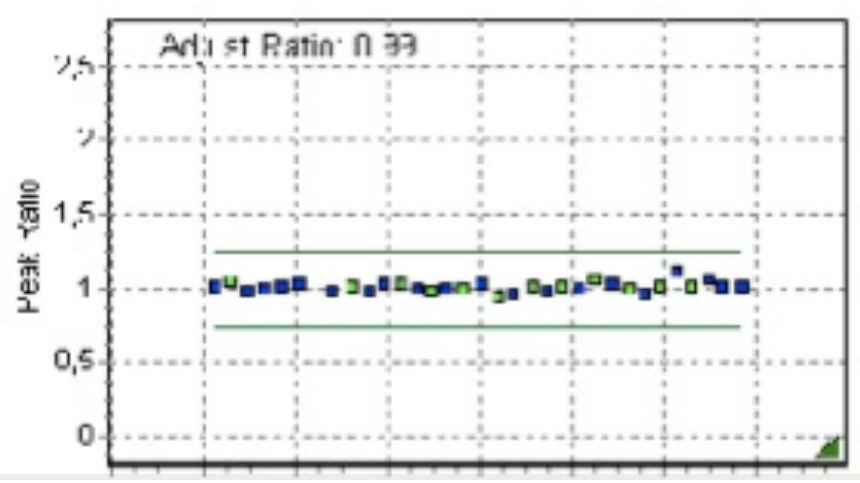

Figura 8 - Resultado de MLPA $^{\circledR}$ negativo (normal). Cada quadrado no gráfico representa o pico de uma sonda. $O$ resultado indica que não há microdeleção pois as sondas da região de SWB estão em igual proporção a das sondas controle.

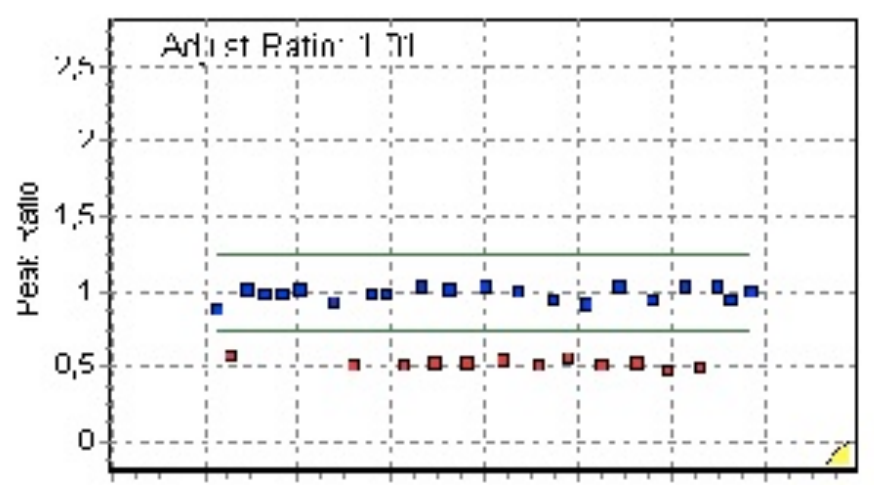

Figura 9 - Resultado de MLPA ${ }^{\circledR}$ positivo. Os quadrados vermelhos indicam os picos das sondas da região da SWB, os quais estão com uma razão de 0,5 em relação às sondas controle, indicando a hemizigozidade

\subsection{Estatística}

Foi investigada a associação dos achados clínicos dos pacientes (fácies típica, baixa estatura, microcefalia, atraso do DNPM, comportamento hipersociável, hiperacusia, cardiopatia, queixas geniturinárias, hipertensão 
arterial) e a presença de microdeleção detectada pelo MLPA $^{\circledR}$ pelo teste de Fisher. Em todas as análises foi adotado um nível de significância de $5 \%$. 0 software utilizado para os cálculos foi o GraphPad InStat versão 3.01. 
4 RESULTADOS 


\section{RESULTADOS}

Dos 65 pacientes avaliados, 40 eram do sexo masculino e 25 do sexo feminino (proporção $M: F=1,6$ ). A idade ao diagnóstico clínico da SWB, variou de 2 meses a 56 anos e 3 meses (mediana $=4$ anos). Todos os pacientes eram filhos de pais normais. Dois gêmeos aparentemente idênticos (Figura 10) tinham SWB e eram os únicos casos da família. Entretanto, teste de zigosidade não foi realizado.

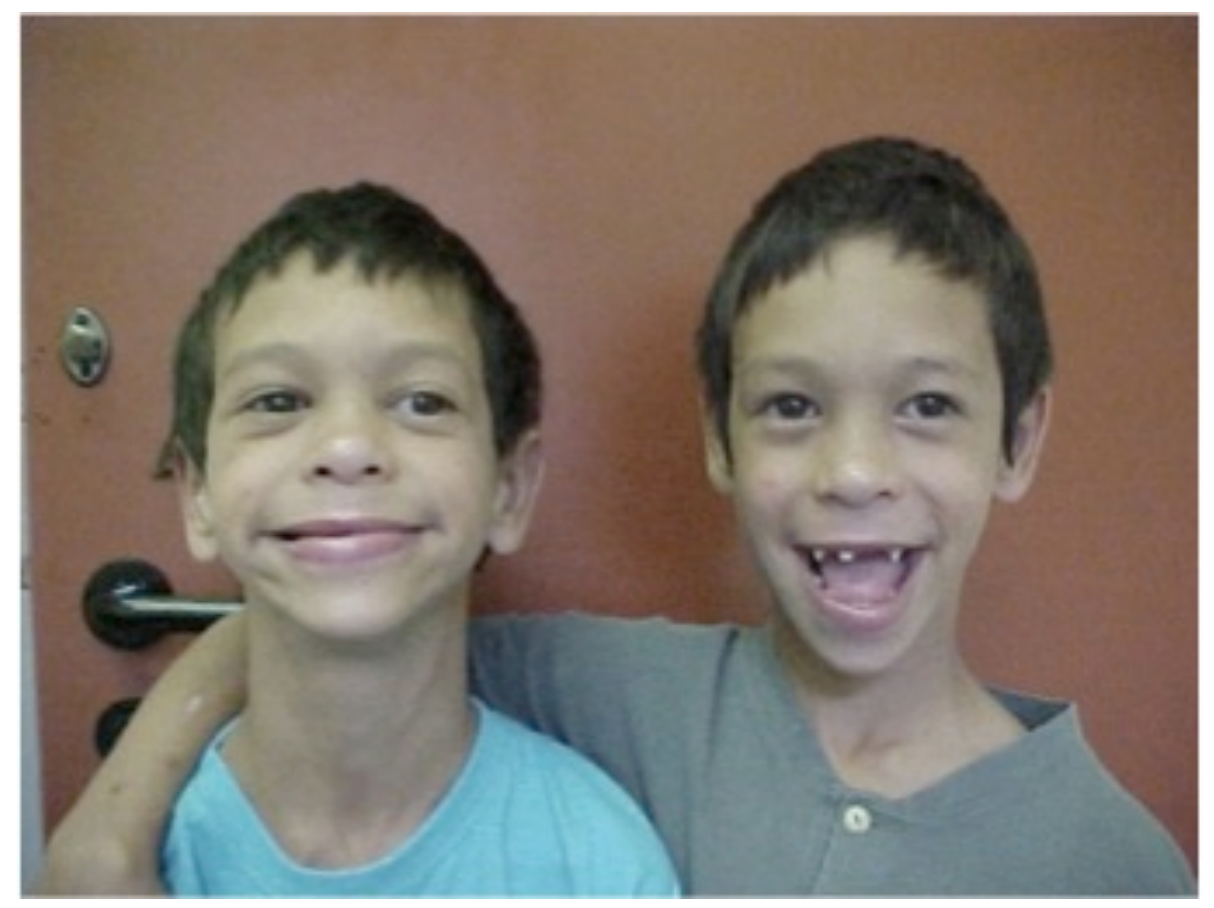

Figura 10 - Gêmeos com SWB, aos 11 anos 


\subsection{Pacientes com microdeleção típica}

A microdeleção na região $7 q 11.23$ foi detectada por $\mathrm{MLPA}^{\circledR}$ em 55/65 pacientes $(84,6 \%)$.

Dos 55 pacientes com microdeleção típica, 21 apresentavam também resultados de FISH realizados previamente pela Unidade de Genética do Instituto da Criança em parceria com o Fleury, ou em outro serviço. Dentre estes, 14 apresentavam FISH e MLPA positivo (concordância em 100\% dos casos). Em cinco casos, o FISH era negativo. Destes, três também apresentavam MLPA negativo, porém dois pacientes, com quadro clínico típico da SWB, apresentavam MLPA positivo. Os resultados das análises de marcadores polimórficos de DNA estavam disponíveis para 40 pacientes. Os 34 pacientes que apresentavam microdeleção na análise de marcadores também apresentaram MLPA positivo. Cinco pacientes apresentavam resultados normais por marcadores e MLPA negativo para a SWB. Um paciente apresentava análise por marcadores inconclusiva e MLPA negativo.

Os principais achados clínicos de pacientes com microdeleção típica foram: fácies típica $(98,2 \%)$, atraso do DNPM $(98,2 \%)$, comportamento hipersociável (94,5\%), hiperacusia $(94,5 \%)$ e cardiopatia (81,8\%). Foi encontrada associação estatisticamente significante entre esses achados e presença de microdeleção (Tabela 2). 
Tabela 2 - Características dos pacientes com microdeleção típica e sem microdeleção em 7q11.23 detectada por MLPA ${ }^{\circledR}$

\begin{tabular}{|c|c|c|c|}
\hline ACHADOS CLÍNICOS & $\begin{array}{c}\text { COM } \\
\text { DELEÇÃO } \\
(n=55)\end{array}$ & $\begin{array}{c}\text { SEM } \\
\text { DELEÇÃO } \\
(n=9)\end{array}$ & $\mathbf{P}^{1}$ \\
\hline Fácies típica ${ }^{2}$ & 54 & 3 & $<0,001$ \\
\hline Atraso DNPM ${ }^{3}$ & 54 & 7 & 0,0495 \\
\hline Comportamento hipersociável & 52 & 5 & 0,0056 \\
\hline Hiperacusia & 52 & 6 & 0,0320 \\
\hline Queixas geniturinárias & 47 & 4 & 0,0131 \\
\hline Cardiopatia & 45 & 4 & 0,0267 \\
\hline Baixa estatura & 24 & 1 & 0,0781 \\
\hline Hipertensão arterial & 20 & 2 & 0,7067 \\
\hline Microcefalia & 17 & 3 & 1,0000 \\
\hline
\end{tabular}

(1) Valor de $p$ estatisticamente significante quando $<0,05$

(2) Foi considerada fácies típica quando o critério craniofacial do escore para SWB proposto pelo Comitê de Genética da Academia Americana de Pediatria (2001) era preenchido / pontuado

(3) DNPM = desenvolvimento neuropsicomotor

As Figuras 11 e 12 mostram a face de alguns dos pacientes estudados com as características típicas da SWB e microdeleção detectada pelo MLPA $^{\circledR}$. 


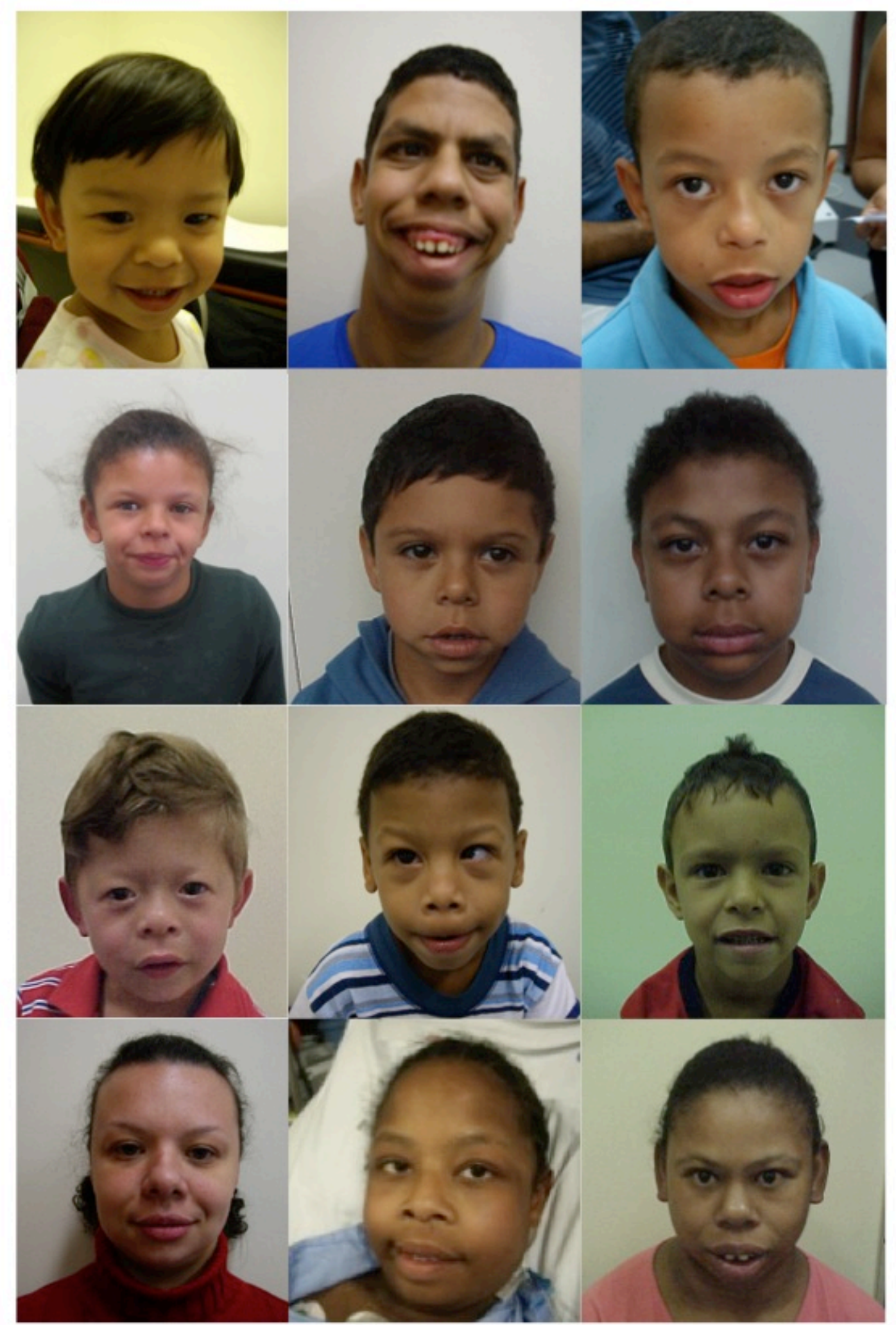

Figura 11 - Pacientes com microdeleção típica 


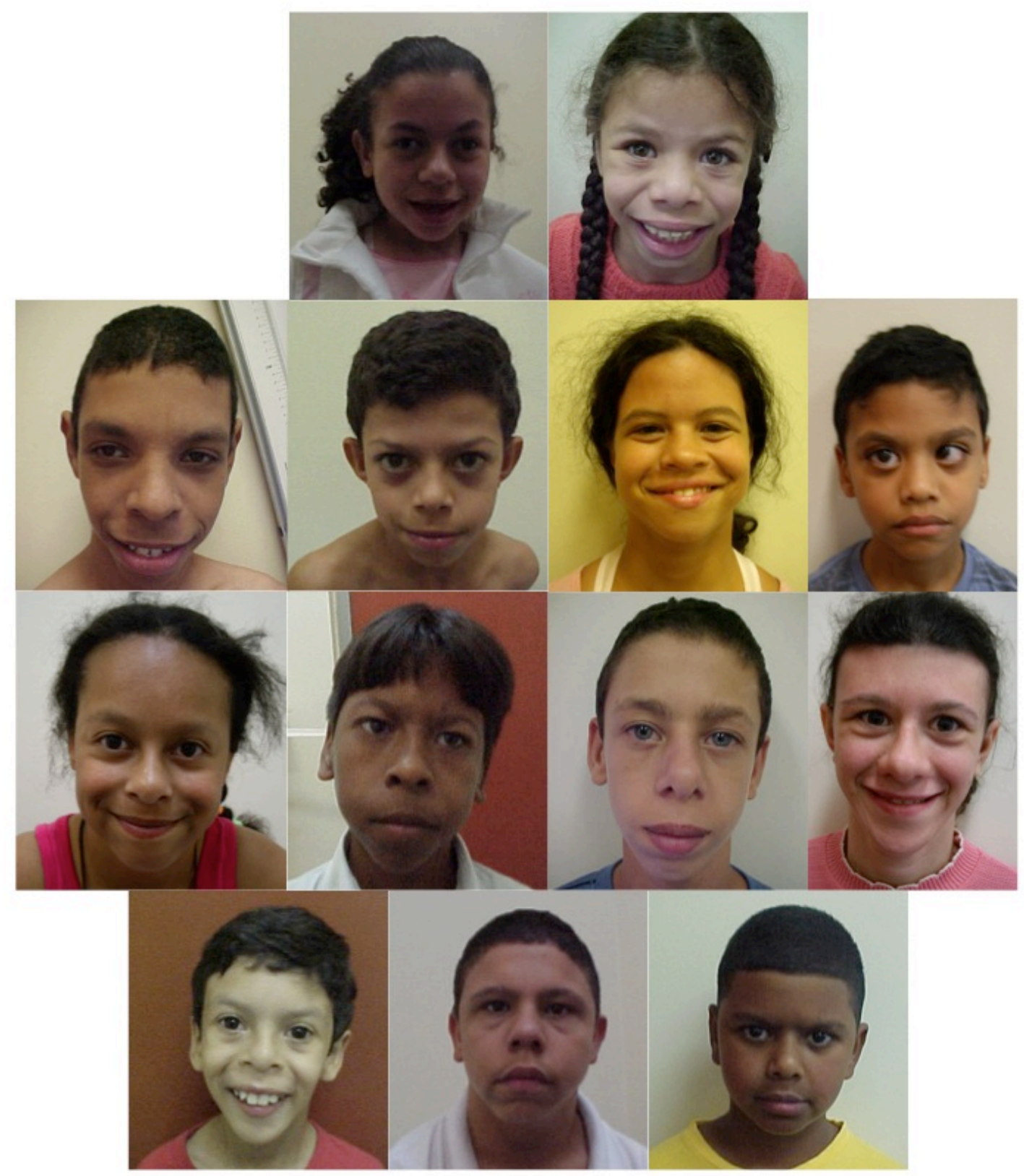

Figura 12 - Pacientes com microdeleção típica

A cardiopatia congênita estava presente em 45 pacientes $(81,8 \%)$, sendo que 19/45 (42,2\%) apresentavam EASV (12 eram EASV isolada e 7 eram casos com associação a outras anomalias cardíacas), três apresentavam laudo de ecocardiograma de "estenose aórtica", sem especificar se era supravalvar, $12 / 45(26,7 \%)$ apresentavam estenose 
pulmonar e 14/45 (31,1\%) pacientes apresentavam outras cardiopatias isoladas ou em associação (tipos de cardiopatias detectadas: prolapso de valva mitral, coarctação de aorta, estenose de artérias pulmonares, comunicação interatrial, comunicação interventricular, insuficiência tricúspide, insuficiência pulmonar, insuficiência mitral, valva aórtica bicúspide). Uma paciente com EASV corrigida cirurgicamente na infância evoluiu com insuficiência cardíaca congestiva e indicação de transplante cardíaco aos 19 anos. O transplante foi realizado por equipe experiente (InCor), porém a paciente apresentou infecção no período pós-transplante e foi a óbito. Outros dois pacientes, um com 13 anos, após segunda cirurgia para correção de estenose de artérias renais, e outro com 19 anos, também foram a óbito por complicações cardiovasculares. Dez pacientes com deleção $(18,2 \%)$ não apresentavam cardiopatia.

Outros achados nos pacientes com deleção foram: microcefalia $(30,9 \%)$ e baixa estatura $(43,6 \%)$ cujas frequências não tiveram diferença estatisticamente significante em relação aos pacientes sem deleção. Dos 17 pacientes com microcefalia, 13 eram do sexo feminino. Em relação à baixa estatura, foi encontrada proporção igual entre os sexos (12 pacientes do sexo masculino e 12 do sexo feminino).

Hipercalcemia foi detectada em um paciente apenas, com um ano e sete meses. Entretanto, um outro paciente apresentou níveis séricos de cálcio no limite superior. Outros dois pacientes apresentaram nefrocalcinose e um paciente apresentou hipercalciúria, com níveis de cálcio sérico normais. 
O hipotireoidismo não-congênito foi encontrado em oito $(14,5 \%)$ pacientes. Esses pacientes estavam em tratamento medicamentoso com acompanhamento por endocrinologistas. Outros quatro pacientes $(7,3 \%)$ apresentavam hipotireoidismo subclínico, ou seja, apenas níveis elevados de TSH. Nenhum dos pacientes estudados apresentou níveis glicêmicos de jejum anormais durante o período de avaliação.

Dezenove pacientes (34,5\%) apresentavam estrabismo e $20(36,4 \%)$ apresentavam hérnias (umbilicais e/ou inguinais).

Em relação a queixas geniturinárias, estavam presentes em 47 dos 55 $(85,4 \%)$ pacientes, principalmente urgência miccional e enurese noturna.

Vinte pacientes $(36,4 \%)$ apresentavam pressão arterial acima dos níveis considerados normais para idade, sexo e percentil de estatura. A idade dos pacientes hipertensos variou de 4 a 23 anos. Quatro pacientes desses 20 (20\% dos pacientes hipertensos, portanto) tiveram estenose de artérias renais, constituindo-se o fator etiológico da hipertensão arterial nesses casos. Três pacientes foram submetidos a cirurgia para correção dessas estenoses (idades: 7-13 anos). Um desses pacientes necessitou de duas intervenções, a primeira aos oito anos e a segunda aos 11 anos de idade. Um paciente de três anos aguarda cirurgia.

Escoliose estava presente em $31 / 55$ pacientes $(56,4 \%)$ e sinostose radioulnar foi observada radiologicamente em $6 / 55$ pacientes $(10,9 \%)$.

Todos os pacientes com deleção apresentavam atraso em pelo menos um marco do DNPM e/ou deficiência intelectual com dificuldade escolar e algum tipo de assistência na idade adulta. Uma paciente apresentou 
síndrome do pânico e um paciente apresentava alucinações visuais.

Algumas manifestações clínicas raramente descritas nos pacientes com SWB foram encontradas no nosso grupo de pacientes, entre elas: obstrução do canal lacrimal $(n=3)$, fusões vertebrais (2 pacientes com fusões em nível cervical e um paciente com fusão lombo-sacral), baços acessórios ( $n=1)$, nódulo escrotal $(n=1)$, hipertrofia de grandes lábios $(n=1)$, craniossinostose sagital $(n=1)$, dente neonatal $(n=1)$ e hérnias musculares em membros inferiores $(n=1)$.

A idade atual dos pacientes com microdeleção típica variou de 2 a 30 anos (mediana de 14 anos).

\subsection{Paciente com microdeleção atípica}

Um paciente foi incluído no estudo devido a EASV e dificuldade escolar, sem fenótipo facial ou comportamental típico de SWB (Figura 13). Foi encontrada uma microdeleção atípica pequena, estimada entre $163 \mathrm{~Kb}$ e $282 \mathrm{~Kb}$, além de microduplicação na região 22q11, a qual continha uma sonda que funcionava como controle no kit. Na região deletada encontramse os genes ELN, LIMK1, EIF4H, LAT2 e RFC2. Foi realizado o teste psicológico e constatado déficit visuoespacial importante, que pode estar relacionado à deleção do gene LIMK1. 


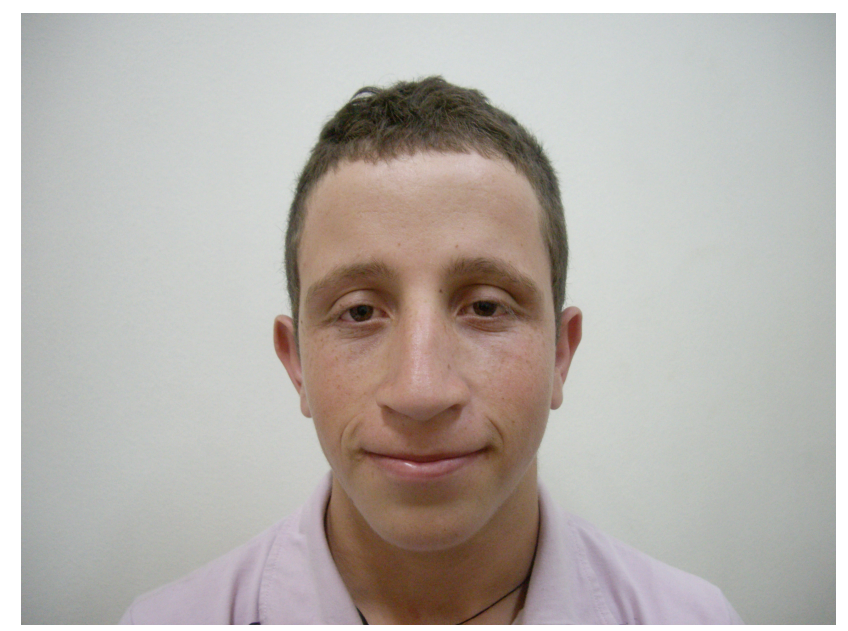

Figura 13 - Paciente com microdeleção atípica, aos 18 anos

\subsection{Pacientes sem microdeleção}

Os nove pacientes sem microdeleção foram justamente os que tinham um diagnóstico clínico mais duvidoso, com algumas características faciais e/ou comportamentais sugestivas de SWB e/ou cardiopatia (Figura 14). Entre os pacientes sem microdeleção ao $\mathrm{MLPA}^{\circledR}$, apenas três tinham resultados de $\mathrm{FISH}$ disponíveis, e seis tinham resultados de marcadores polimórficos, sendo com essa metodologia cinco também negativos para a SWB e um inconclusivo. 


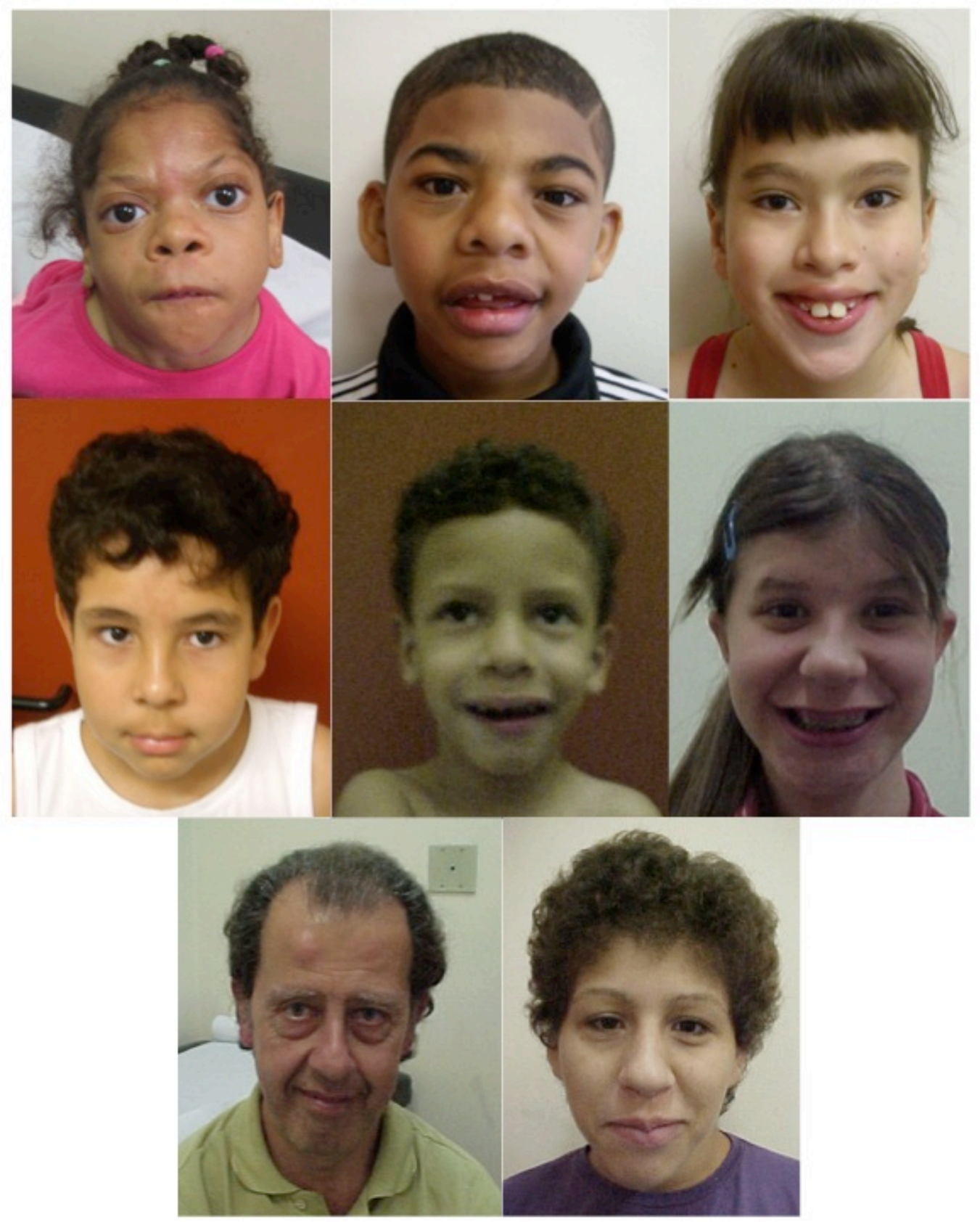

Figura 14 - Pacientes com MLPA ${ }^{\circledR}$ negativo (ausência de microdeleção) 
5 DISCUSSÃO 


\section{DISCUSSÃO}

A idade ao diagnóstico da SWB variou de 2 meses a 56 anos e 3 meses (mediana $=4$ anos). Às vezes, o diagnóstico pode ser pensado antes dos dois anos de idade naqueles com EASV por aqueles cardiologistas que sabem que essa cardiopatia é a principal encontrada na SWB. Entretanto, alguns pacientes sem cardiopatia muitas vezes só são diagnosticados depois que ocorre atraso do DNPM, apresentação de comportamento hipersociável típico e quando um médico mais familiarizado com a síndrome reconhece a fácies típica. Outro ponto a ser considerado em relação ao diagnóstico é que casos graves de hipercalcemia neonatal podem levar a óbito antes que um possível diagnóstico de SWB pudesse ser aventado. Por serem os primeiros médicos que muitas vezes têm contato com esses pacientes, os neonatologistas devem estar atentos a recém-nascidos com hipercalcemia neonatal e/ou crescimento intrauterino restrito e EASV para considerarem a SWB como possível diagnóstico.

Em relação à frequência de cardiopatia $(81,8 \%)$, ao tipo mais prevalente (EASV em 42,2\%) e aos tipos de cardiopatia encontrados nos pacientes estudados, estão em concordância com a literatura (ou seja, cerca de $75 \%$ possuem cardiopatia e a mais prevalente é a EASV). Como uma grande parte dos pacientes do serviço são encaminhados pela Associação de Pacientes e não pela Cardiologia, isso pode ter sido fator determinante para que a prevalência de EASV esteja abaixo de 50\% em nossa casuística. 
Apesar de EASV ser um sinal de alerta importante para a síndrome, não se constitui um sinal patognomônico da SWB. No caso do paciente com microdeleção parcial da região da SWB, a presença da EASV pode ser justificada pela deleção do gene da elastina. Provavelmente, a ausência nesse paciente das outras características cardinais da síndrome ocorreu devido ao pequeno tamanho de sua microdeleção, o que o poupou dos efeitos da haploinsuficiência de genes importantes para o fenótipo completo da SWB.

É importante salientar que a ausência de cardiopatia não afasta o diagnóstico da SWB. A ausência de cardiopatia em alguns pacientes com resultados positivos, seja por $\mathrm{MLPA}^{\circledR}$ ou outra técnica que utilize o gene da elastina como marcador, é intrigante pois, se deleções ou outras mutações nesse gene têm sido implicadas como responsáveis pela EASV, seria esperado a presença de cardiopatia em todos os pacientes com deleções em 7q11.23 envolvendo esse gene. Por isso, efeitos epigenéticos, como o efeito da variação do número de cópias de outras regiões do genoma, devem ser considerados.

O óbito de três pacientes por complicações cardiovasculares demonstra o peso desse tipo de manifestação na morbidade e na mortalidade dos pacientes com SWB. Um desses foi submetido a transplante cardíaco. Não há relatos anteriores desse tipo de cirurgia em pacientes com SWB.

A frequência dos outros achados clínicos dos pacientes desse estudo se equiparou à relatada na literatura em relação aos dismorfismos faciais, comportamento hipersociável, atraso do DNPM, hiperacusia, baixa estatura 
e microcefalia. Entretanto, apesar de hipercalcemia ter sido uma característica descrita nos relatos iniciais da SWB, foi detectada somente em uma paciente desse estudo. Como muitas vezes a hipercalcemia se manifesta nos primeiros anos de vida, muitos pacientes podem até ter apresentado essa manifestação. Todavia, como a medição de cálcio sérico não é uma rotina nos berçários ou pronto-socorros pediátricos, além de o paciente muitas vezes não ter ainda o diagnóstico da SWB na infância (o que poderia alertar o neonatologista ou pediatra a solicitar uma dosagem sérica desse eletrólito), este pode ser um viés em nossa análise. Além disso, alguns pacientes apresentam hipercalcemia ao longo da vida e alguns dos pacientes de nosso estudo podem não ter apresentado essa alteração exatamente durante o período do estudo. Portanto, devem continuar a ser monitorados quanto à possibilidade de distúrbio do cálcio periodicamente (American Academy of Pediatrics, 2001; Pober and Morris, 2007).

A prevalência de alterações da tireóide nos pacientes do presente estudo $(14,5 \%$ e $7,3 \%$ de hipotireoidismo e hipotireoidismo subclínico respectivamente) fica entre os números encontrados na literatura, que ainda é controversa, com números variando de 2 a $38 \%$ (American Academy of Pediatrics, 2001; Selicorni et al., 2006). A possibilidade de agravamento de algumas manifestações clínicas da SWB pelo hipotireoidismo e a possibilidade de tratamento dessa condição justificam o acompanhamento de rotina dos níveis de TSH e T4 livre, bem como o inquérito de sinais e sintomas de hipotireoidismo nos pacientes com SWB. A orientação na literatura atual é de acompanhamento dos níveis de hormônios da tireóide a 
cada dois anos (American Academy of Pediatrics, 2001); entretanto, em nosso protocolo, no qual a testagem foi anual, vários casos de hipotireoidismo foram diagnosticados e poderiam ter tido atraso diagnóstico caso a periodicidade dos exames fosse em intervalo maior. Apesar de diabetes mellitus ser outra complicação endocrinológica descrita na SWB, (Pober and Morris, 2007) nenhum dos pacientes estudados apresentou alterações nos níveis glicêmicos de jejum. Entretanto, os pacientes do nosso estudo eram em sua maioria crianças e adolescentes e essa é uma manifestação mais frequente na idade adulta (Pober e Morris, 2007; Pober et al., 2010).

As frequências de outras manifestações da SWB observadas nesse estudo, tais como estrabismo, hérnias, escoliose e sinostose radioulnar, foram concordantes com os números e variações descritos na literatura (Greenberg e Lewis, 1988; Perez Jurado et al., 1996; American Academy of Pediatrics, 2001; Bedeschi et al., 2011). Por outro lado, as queixas geniturinárias tiveram uma prevalência um pouco superior ao descrito por outros grupos ( $85,4 \%$ no presente estudo versus 50 a $68 \%$ na literatura) (Perez Jurado et al., 1996; American Academy of Pediatrics, 2001), o que pode refletir o fato de todos os pacientes de nossa casuística serem encaminhados para avaliação basal pela equipe de Urologia.

Hipertensão arterial foi detectada em 20/55 pacientes (36,4\%). Um paciente apresentou hipertensão aos quatro anos de idade, o que nos alerta para a ocorrência dessa complicação ainda na infância. Na literatura, há relatos de hipertensão arterial em cerca de $50 \%$ dos pacientes com SWB 
(Del Campo et al., 2006), até mesmo em lactentes de 1 mês de vida (Bouchireb et al., 2010). No presente estudo, 4/20 (20\%) tinham estenose de artérias renais. Um paciente faleceu após a segunda cirurgia de correção de estenose de artérias renais bilaterais aos 13 anos. $\mathrm{Na}$ literatura, a hipertensão renovascular é descrita em $44 \%$ dos pacientes com SWB (Pankau et al., 1996). A possibilidade de estenose de artérias renais ser o fator etiológico, com tratamento efetivo pela indicação de tratamento cirúrgico, deve alertar todo profissional de saúde que lida com pacientes com SWB a monitorar a pressão arterial (American Academy of Pediatrics, 2001) e solicitar avaliação das artérias renais caso se encontrem valores anormais para a faixa etária, incluindo crianças pequenas.

A ocorrência de outros achados menos frequentes e menos específicos da SWB nesse estudo (por exemplo, baços acessórios, dente neonatal, craniossinostose, hérnias musculares em membros inferiores) e sua relação com essa síndrome não pode ser determinada, uma vez que o número de pacientes com cada uma dessas manifestações foi pequeno. A estenose de canal lacrimal já foi descrita na SWB (Pober, 2010). Um paciente apresentava luxações recorrentes de patelas, anormalidade essa já descrita em alguns pacientes com SWB (Morris et al., 2010).

Tendo em vista a relativa alta prevalência de problemas neurológicos, endocrinológicos, cardíacos, oftalmológicos, ortopédicos, urológicos, nefrológicos, psiquiátricos, entre outros, a avaliação dos pacientes com SWB por profissionais dessas especialidades se mostra de grande relevância. 
Além disso, muitas crianças necessitam de fisioterapia e/ou fonoterapia para ajudá-las em seu desenvolvimento.

Um paciente incluído no estudo teve uma microdeleção parcial na região $7 q 11.23$ detectada por $M_{L P A}{ }^{\circledR}$. Uma vez que ele não apresenta muitas das características clínicas da SWB, como os dismorfismos faciais e comportamento típicos, esse paciente poderia ser classificado como "SVASplus", com tradução em português de fenótipo "EASV-mais" (Morris e Mervis, 2000).

Assim como descrito na literatura (Tassabehji, 2003), a homogeneidade no tamanho da microdeleção, mesmo em pacientes com características variáveis da SWB, dificulta uma correlação genótipo-fenótipo direta. Em contrapartida, indivíduos com microdeleções atípicas e fenótipo incompleto da síndrome podem ser relativamente informativos quando é possível a comparação das manifestações clínicas e os potenciais papeis de cada gene envolvido na região deletada.

Até o presente momento, o FISH constitui-se padrão-ouro para o diagnóstico da SWB. Dentre os pacientes com MLPA positivo, 14 apresentavam FISH, com resultado também positivo (concordância em $100 \%$ dos casos). Em cinco casos, o FISH era negativo. Destes, três também apresentavam MLPA negativo, porém dois pacientes, com quadro clínico típico da SWB (Figura 15), apresentavam FISH negativo, realizado em outro serviço e MLPA positivo. A análise por marcadores polimórficos de DNA também detectou a microdeleção. O FISH de um desses pacientes foi 
repetido em outro serviço, confirmando dessa vez a microdeleção na região da SWB.

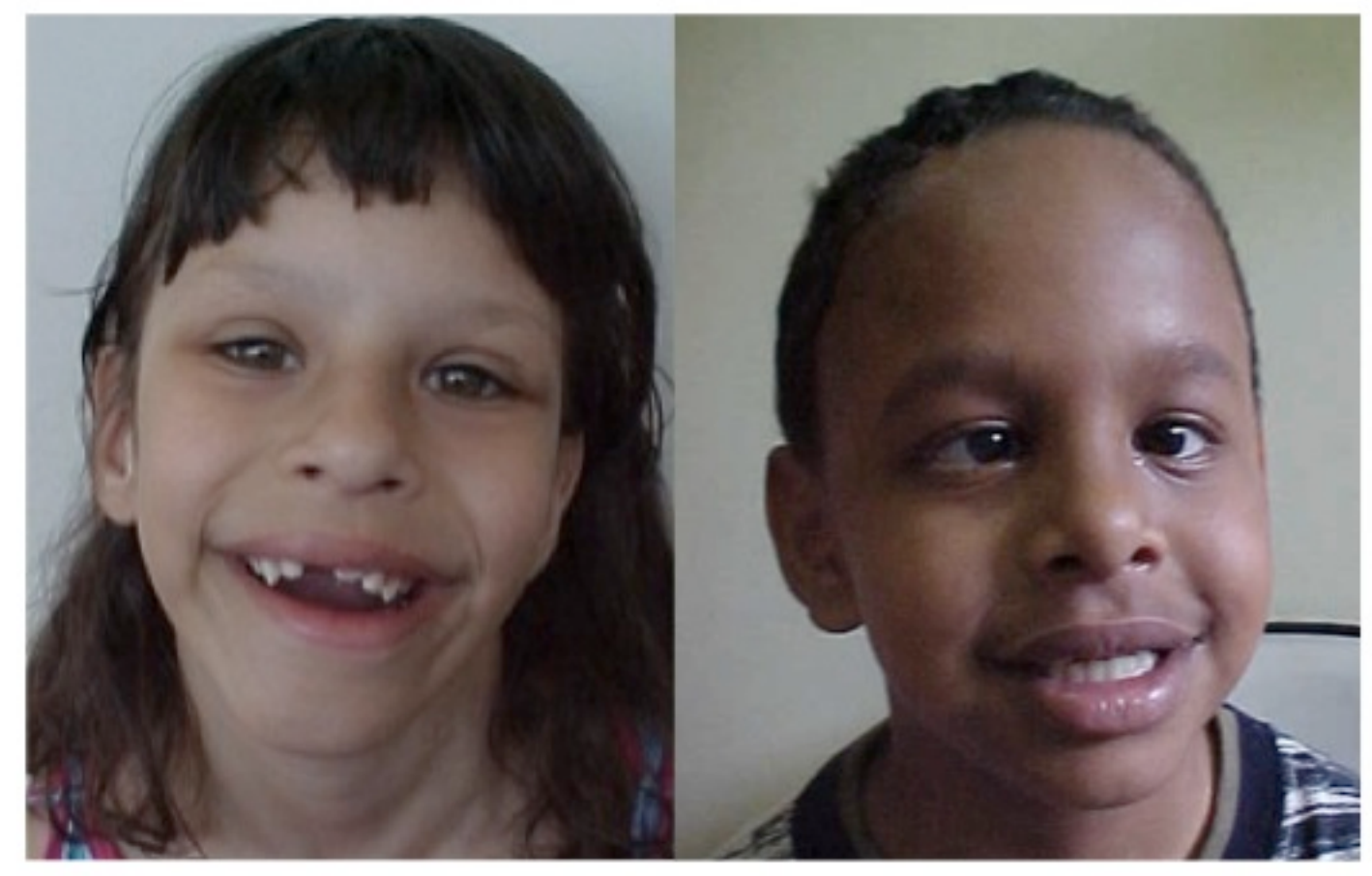

Figura 15 - Pacientes com FISH negativo e MLPA ${ }^{\circledR}$ positivo para a SWB

Os resultados das análises de marcadores polimórficos de DNA estavam disponíveis para 40 pacientes e foram concordantes com o MLPA em todos os casos em que os marcadores foram informativos (houve apenas um caso com análise de marcadores inconclusiva).

A concordância dos resultados em comparação com outros métodos diagnósticos já conhecidos indica que a técnica de MLPA ${ }^{\circledR}$ é uma alternativa promissora para a detecção da microdeleção em 7q11.23, permitindo a confirmação diagnóstica de SWB. 
6 CONCLUSÕES 


\section{CONCLUSÕES}

- A técnica de $M L P A^{\circledR}$ foi capaz de detectar da microdeleção na região 7q11.23 possibilitando a confirmação diagnóstica da SWB em 55/65 $(84,6 \%)$ dos pacientes estudados. Foi possível detectar uma microdeleção menor atípica em um paciente cujo quadro não constitui SWB, mas sim "SVAS-plus".

- Para os pacientes que tinham resultados de FISH disponíveis, houve concordância de 100\% nos resultados positivos (14 FISH e MLPA positivos). Dos pacientes com FISH negativos, tinham resultados de MLPA concordantes (negativos). Dois pacientes com diagnóstico clínico de SWB e resultados de FISH negativos tiveram microdeleção na região $7 q 11.23$ confirmada por $\mathrm{MLPA}^{\circledR}$ e marcadores polimórficos de DNA.

- Para os pacientes que tinham resultados de marcadores polimórficos disponíveis, a concordância dos resultados foi de 100\% (34 pacientes tinham marcadores e MLPA positivos; cinco pacientes tinham marcadores e MLPA negativos).

- Os principais achados clínicos de pacientes com deleção foram: fácies típica $(98,2 \%)$, atraso de DNPM $(98,2 \%)$, comportamento hipersociável $(94,5 \%)$, hiperacusia $(94,5 \%)$ e cardiopatia $(81,8 \%)$. Foi encontrada associação estatisticamente significante entre a presença desses achados clínicos e a presença de microdeleção. 
- Outros achados nos pacientes com microdeleção foram: microcefalia $(30,9 \%)$ e baixa estatura (43,6\%). A frequência desses achados não teve diferença estatisticamente significante em relação aos pacientes sem microdeleção.

- A cardiopatia congênita estava presente em 45 pacientes $(81,8 \%)$, sendo que $19 / 45(42,2 \%)$ apresentavam EASV (12 eram EASV isolada e 7 eram casos com associação a outras anomalias cardíacas). Três pacientes morreram por complicações cardíacas, mesmo com acompanhamento clínico e intervenções cirúrgicas corretivas, demonstrando o impacto da cardiopatia como fator de mortalidade nessa síndrome.

- A hipertensão arterial precoce (4- 23 anos) foi encontrada em 20/55 $(36,4 \%)$ dos pacientes. Entre os pacientes hipertensos, 4/20 apresentaram estenose de artérias renais.

- Queixas geniturinárias estavam presentes em $85,4 \%$ dos casos, principalmente urgência miccional e enurese noturna.

- O hipotireoidismo foi encontrado em 14,5\% e hipotireoidismo subclínico estava presente em 7,3\% dos pacientes com microdeleção típica.

- A ocorrência de problemas neurológicos, endocrinológicos, oftalmológicos, urológicos, renovasculares e psiquiátricos, bem como complicações cardíacas, acarreta a necessidade de avaliação por profissionais dessas especialidades. $O$ acompanhamento multidisciplinar e a comunicação harmoniosa entre esses profissionais 
contribuem para o manejo efetivo desses pacientes.

- A confirmação diagnóstica da SWB permite um acompanhamento antecipatório para a detecção precoce de complicações, aconselhamento genético e orientação aos pais. 
7 ANEXOS 
ANEXO A - Folha de aprovação do estudo pela Comissão de Ética para Análise de Projetos de Pesquisa - CAPPesq da diretoria clínica do Hospital das Clínicas e da Faculdade de Medicina da Universidade de São Paulo

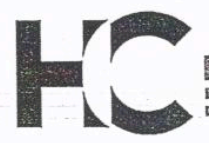

MOSPITU BAS GLIEICAS

DA FACULDADE DE MEDICINA

\section{APROVAÇÃO}

A Comissão de Ética para Análise de Projetos de Pesquisa - CAPPesq da Diretoria Clínica do Hospital das Clínicas e da Faculdade de Medicina da Universidade de São Paulo, em sessão de 23/04/2008, APROVOU o Protocolo de Pesquisa n 0111/08, intitulado: "DETECÇÃO DA MICRODELEÇÃO 7Q11.23 POR MLPA E ESTUDO CLÍNICO DOS PACIENTES COM SÍNDROME DE WILLIAMS-BUEREN" apresentado pelo Departamento de PEDIATRIA, inclusive o Termo de Consentimento Livre e Esclarecido.

Cabe ao pesquisador elaborar e apresentar à CAPPesq, os relatórios parciais e final sobre a pesquisa (Resolução do Conselho Nacional de Saúde n 196, de 10/10/1996, inciso IX.2, letra "c").

Pesquisador (a) Responsável: Dra. Chong Ae Kim

Pesquisador (a) Executante: Rachel Sayuri Honjo

CAPPesq, 25 de Abril de 2008

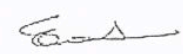

Prof. Dr. Eduardo Massad Presidente da Comissão de Ética para Análise de Projetos de Pesquisa

Comissão de Ética para Análise de Projetos de Pesquisa do HCFMUSP e da FMUSP Diretoria Clinica do Hospital das Clinicas da Faculdade de Medicina da Universidade de São Paulo Rua Ovidio Pires de Campos, 255, 5 andar - CEP 05403010 - Săo Paulo - SP Fone: 0113069 6442 Fax: 01130696492 e-mail: cappesq@hcnet.usp.br/secretariacappesq2@hcnet.usp.br 
ANEXO B - Termo de Consentimento Livre e Esclarecido

HOSPITAL DAS CLÍNICAS DA FACULDADE DE MEDICINA DA UNIVERSIDADE DE SÃO PAULO-HCFMUSP

TERMO DE CONSENTIMENTO LIVRE E ESCLARECIDO

DADOS DE IDENTIFICAÇÃO DO SUJEITO DA PESQUISA OU RESPONSÁVEL LEGAL

1. NOME:

DOCUMENTO DE IDENTIDADE No

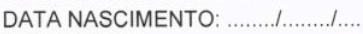

ENDEREÇO

BAIRRO

CEP:.

SEXO: M $\square$ F $\square$

........... No

APTO:

CIDADE

TELEFONE: DDD (............)

2.RESPONSÁVEL LEGAL

NATUREZA (grau de parentesco, tutor, curador etc.)

DOCUMENTO DE IDENTIDADE SEXO: M $\square$ F

DATA NASCIMENTO.

ENDEREÇO:

BAIRRO:

$\ldots \ldots \ldots \ldots$

№................ APTO

CEP

TELEFONE: DDD CIDADE:

DADOS SOBRE A PESQUISA

1. TITULO DO PROTOCOLO DE PESQUISA: DETECÇÃO DA MICRODELEÇÃO 7q11.23 POR MLPA E ESTUDO CLÍNICO DOS PACIENTES COM SINDROME DE WILLIAMS-BEUREN

2. PESQUISADOR: Dra Chong Ae Kim

CARGO/FUNÇÃO: Chefe da Unidade de Genética do Instituto da Criança do HC-FMUSP INSCRIÇÃO CONSELHO REGIONAL No 40054

UNIDADE DO HCFMUSP: Unidade de Genética do Instituto da Criança

3. AVALIAÇÃO DO RISCO DA PESQUISA:

$\begin{array}{ll}\text { RISCO MINIMO } X & \text { RISCO MÉdIO } \\ \text { RISCO BAIXO } \square & \text { RISCO MAIOR }\end{array}$

4. DURAÇÃO DA PESQUISA : 2 anos 
1 - Os objetivos desse estudo são: (1) comparar as diferentes metodologias disponíveis (citogenética clássica, FISH, marcadores polimórficos de DNA e MLPA) na investigação da deleção 7q11.23 nos pacientes com síndrome de Williams-Beuren; (2) avaliar as manifestações clínicas e a evolução de pacientes com diagnóstico de síndrome de Williams-Beuren; (3) correlacionar o quadro clínico e a evolução de pacientes com $\circ$ resultado de exame do material genético (DNA). 2 - Serão realizados entrevista com os pais e exame físico dos pacientes com diagnóstico de síndrome de Williams-Beuren, coleta de sangue periférico do paciente e de seus pais.

3 - A entrevista com os pais e o exame físico dos pacientes serão realizados em consulta médica previamente agendada. A coleta de sangue será por punção periférica da veia do antebraço. 4 - Desconfortos e riscos esperados: apenas os correspondentes à coleta de sangue de veia periférica,

exames para avaliar o coração, o comportamento, os olhos e a pressão arterial que por ventura forem solicitados.

5 - Benefícios que poderão ser obtidos: contribuir para o entendimento da contribuição do material genético nas manifestações da síndrome de Williams-Beuren e sua evolução, o que pode orientar mais adequadamente os pais e profissionais de saúde no acompanhamento dos pacientes.

6 - Relação de procedimentos alternativos que possam ser vantajosos, pelos quais o paciente pode optar:

nenhum

7 - Garantia de acesso: em qualquer etapa do estudo, você terá acesso aos profissionais responsáveis pela pesquisa para esclarecimento de eventuais dúvidas. O principal investigador é a Dra Chong $\mathrm{Ae}$ Kim, que pode ser encontrado no endereço Av. Dr Enéas Carvalho de Aguiar, 647 -Telefone (11)30698671. Se você tiver alguma consideração ou dúvida sobre a ética da pesquisa, entre em contato com o Comitê de Ética em Pesquisa (CEP) - Rua Ovídio Pires de Campos, 225 - $5^{\circ}$ andar - tel: 3069-6442 ramais 16, 17, 18 ou 20, FAX: 3069-6442 ramal 26 - E-mail: cappesq@hcnet.usp.br 8 - É garantida a liberdade da retirada de consentimento a qualquer momento e deixar de participar do estudo, sem qualquer prejuizo à continuidade de seu tratamento na Instituição; 09 - Direito de confidencialidade - As informações obtidas serão analisadas em conjunto com outros pacientes, não sendo divulgado a identificação de nenhum paciente; 10 - Direito de ser mantido atualizado sobre os resultados parciais das pesquisas, quando em estudos abertos, ou de resultados que sejam do conhecimento dos pesquisadores; 11 - Despesas e compensações: não há despesas pessoais para o participante em qualquer fase do estudo, incluindo exames e consultas. Também não há compensação financeira relacionada à sua participação. Se existir qualquer despesa adicional, ela será absorvida pelo orçamento da pesquisa. 12 - Em caso de dano pessoal, diretamente causado pelos procedimentos ou tratamentos propostos neste estudo (nexo causal comprovado), o participante tem direito a tratamento médico na Instituição, 
bem como às indenizações legalmente estabelecidas. 13 - Compromisso do pesquisador de utilizar os dados e o material coletado somente para esta pesquisa.

Acredito ter sido suficientemente informado a respeito das informações que li ou que foram lidas para mim, descrevendo o estudo "DETECÇÃO DA MICRODELEÇÃO 7q11.23 POR MLPA E ESTUDO CLÍNICO DOS PACIENTES COM SÍNDROME DE WILLIAMS-BEUREN" Eu discuti com a Dra Chong Ae Kim sobre a minha decisão em participar nesse estudo. Ficaram claros para mim quais são os propósitos do estudo, os procedimentos a serem realizados, seus desconfortos e riscos, as garantias de confidencialidade e de esclarecimentos permanentes. Ficou claro também que minha participação é isenta de despesas e que tenho garantia do acesso a tratamento hospitalar quando necessário. Concordo voluntariamente em participar deste estudo e poderei retirar o meu consentimento a qualquer momento, antes ou durante o mesmo, sem penalidades ou prejuízo ou perda de qualquer benefício que eu possa ter adquirido, ou no meu atendimento neste Serviço.

Assinatura do paciente/representante legal Data

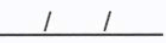

Assinatura da testemunha

Data

para casos de pacientes menores de 18 anos, analfabetos, semi-analfabetos ou portadores de deficiência auditiva ou visual.

\section{(Somente para o responsável do projeto)}

Declaro que obtive de forma apropriada e voluntária o Consentimento Livre e Esclarecido deste paciente ou representante legal para a participação neste estudo. 


\section{ANEXO C - Escore da síndrome de Williams-Beuren}

Crescimento

( ) Pós-termo $>41$ sem

( ) Déficit crescimento $<p 2,5$

( ) Vômitos ou refluxo gastroesofágico

Comportamento e Desenvolvimento
( ) Personalidade amigável
Problemas visual-espacial
( ) Hiperacusia
( ) Ansiedade
( ) Atraso do desenvolvimento ou deficiência mental
( ) Atraso de fala, excesso de fala

Craniofacial

( ) Estreitamento bitemporal

( ) Epicanto ou ponte nasal achatada

( ) Estrabismo

( ) Nariz curto ou narinas antevertidas

( ) Bochechas proeminentes

( ) Filtro longo

( ) Dentes pequenos, espaçados

( ) Boca grande

( ) Lóbulos da orelha proeminentes

Cardiopatias

( ) Estenose aórtica supravalvar

( ) Estenose artéria pulmonar periférica $\geq 3$ score 1 ponto.

( ) Cólica prolongada $>4 \mathrm{~m}$ irritabilidade

( ) Constipação crônica

$\geq 3$ score 1 ponto.

$\geq 8$ score 3 pontos.
( ) Edema periorbitário

( ) Íris de padräo estrelado

( ) Nariz bulboso

( ) Hipoplasia malar

( ) Queixo pequeno

Outros Cardiopatias

( ) Outras cardiopatias

( )Hipertensão arterial

( ) Sopro cardíaco

Tecido Conectivo

( ) Voz rouca

( ) Hérnia inguinal

( ) Divertículo de bexiga ou intestino

( ) Pescoço longo ou ombro caido

$\geq 2$ score 2 pontos.

Cálcio Limitação articular ou frouxidão

( ) Prolapso retal

( ) Hipercalcemia

( ) Hipercalciúria

Achados adicionais:

( ) Prega sacral

() Hipotireoidismo

) Sinostose radioulnar

Outros:

$\geq 1$ score 1 ponto.

Total: pontos

Escore for $<3$ = síndrome de Williams-Beuren improvável

Escore $\geq 3$ = considerar exame molecular

Modificado de Comitê de Genética / Academia Americana de Pediatria, 2001 
ANEXO D - Artigos submetidos ou publicados referentes a este projeto

1) Dutra RL, Honjo RS, Kulikowski LD, Fonseca FM, Pieri PC, Jehee FS, Bertola DR, Kim CA. Copy number variation in Williams-Beuren syndrome: suitable diagnostic strategy for developing countries. BMC. 2012 Jan 9;5-13.

2) Honjo RS, Dutra RL, Nunes MM, Gomy I, Kulikowski LD, Jehee FS, Kim CA. Atypical deletion in Williams-Beuren syndrome critical region detected by MLPA $^{\circledR}$ in a patient with supravalvular aortic stenosis and learning difficulty. Submetido ao Journal of Genetics and Genomics em fevereiro / 2012 - Em análise. 
8 REFERÊNCIAS 


\section{REFERÊNCIAS}

American Academy of Pediatrics: Health care supervision for children with Williams syndrome. Pediatrics. 2001 May;107(5):1192-204.

Actis Dato GM, La Torre M, Caimmi P, Actis Dato A, Jr., Centofanti P, Ottino GM, Di Summa M. Williams-Beuren syndrome. Long-term results of surgical treatments in six patients. J Cardiovasc Surg (Torino). 1997 Apr;38(2):125-9.

Antonell A, Del Campo M, Flores R, Campuzano V, Perez-Jurado LA. [Williams syndrome: its clinical aspects and molecular bases]. Rev Neurol. 2006 Jan 7;42 Suppl 1:S69-75.

Axelsson S. Variability of the cranial and dental phenotype in Williams syndrome. Swed Dent J Suppl. 2005(170):3-67.

Axelsson S, Bjornland T, Kjaer I, Heiberg A, Storhaug K. Dental characteristics in Williams syndrome: a clinical and radiographic evaluation. Acta Odontol Scand. 2003 Jun;61(3):129-36.

Bawden HN, MacDonald GW, Shea S. Treatment of children with Williams syndrome with methylphenidate. J Child Neurol. 1997 Jun;12(4):248-52.

Bayazit AK, Yalcinkaya F, Cakar N, Duzova A, Bircan Z, Bakkaloglu A, Canpolat N, Kara N, Sirin A, Ekim M, Oner A, Akman S, Mir S, Baskin E, Poyrazoglu HM, Noyan A, Akil I, Bakkaloglu S, Soylu A. Reno-vascular hypertension in childhood: a nationwide survey. Pediatr Nephrol. 2007 Sep;22(9):1327-33.

Bayes M, Magano LF, Rivera N, Flores R, Perez Jurado LA. Mutational mechanisms of Williams-Beuren syndrome deletions. Am J Hum Genet. 2003 Jul;73(1):131-51.

Bedeschi MF, Bianchi V, Colli AM, Natacci F, Cereda A, Milani D, Maitz S, Lalatta $F$, Selicorni A. Clinical follow-up of young adults affected by Williams syndrome: experience of 45 Italian patients. Am J Med Genet A. 2011 Feb;155A(2):353-9.

Bellugi U, Lichtenberger L, Jones W, Lai Z, St George M. I. The neurocognitive profile of Williams Syndrome: a complex pattern of strengths and weaknesses. J Cogn Neurosci. 2000;12 Suppl 1:7-29.

Bernard Y, Didier D, Bozio A, Champsaur G, Renaud JC, Maurat JP. [Coronary anomalies associated with the Williams-Beuren syndrome. Apropos of 2 cases]. Arch Mal Coeur Vaiss. 1985 May;78(5):791-5. 
Beuren AJ, Apitz J, Harmjanz D. Supravalvular aortic stenosis in association with mental retardation and a certain facial appearance. Circulation. 1962 Dec;26:1235-40.

Beuren AJ, Schulze C, Eberle P, Harmjanz D, Apitz J. The Syndrome of Supravalvular Aortic Stenosis, Peripheral Pulmonary Stenosis, Mental Retardation and Similar Facial Appearance. Am J Cardiol. 1964 Apr;13:47183.

Biesecker LG, Laxova R, Friedman A. Renal insufficiency in Williams syndrome. Am J Med Genet. 1987 Sep;28(1):131-5.

Bird LM, Billman GF, Lacro RV, Spicer RL, Jariwala LK, Hoyme HE, ZamoraSalinas R, Morris C, Viskochil D, Frikke MJ, Jones MC. Sudden death in Williams syndrome: report of ten cases. J Pediatr. 1996 Dec;129(6):926-31.

Black JA, Carter RE. Association between Aortic Stenosis and Facies of Severe Infantile Hypercalcaemia. Lancet. 1963 Oct 12;2(7311):745-9.

Blomberg S, Rosander M, Andersson G. Fears, hyperacusis and musicality in Williams syndrome. Res Dev Disabil. 2006 Nov-Dec;27(6):668-80.

Bonnet D, Cormier V, Villain E, Bonhoeffer P, Kachaner J. Progressive left main coronary artery obstruction leading to myocardial infarction in a child with Williams syndrome. Eur J Pediatr. 1997 Oct;156(10):751-3.

Borg I, Delhanty JD, Baraitser M. Detection of hemizygosity at the elastin locus by FISH analysis as a diagnostic test in both classical and atypical cases of Williams syndrome. J Med Genet. 1995 Sep;32(9):692-6.

Bouchireb K, Boyer O, Bonnet D, Brunelle F, Decramer S, Landthaler G, Liutkus $A$, Niaudet $P$, Salomon R. Clinical features and management of arterial hypertension in children with Williams-Beuren syndrome. Nephrol Dial Transplant. 2010 Feb;25(2):434-8.

Brewer CM, Morrison N, Tolmie JL. Clinical and molecular cytogenetic (FISH) diagnosis of Williams syndrome. Arch Dis Child. 1996 Jan;74(1):5961.

Burn J. Williams syndrome. J Med Genet. 1986 Oct;23(5):389-95.

Bzduch V, Spissak L, Berankova M, Bircak J. [Congenital radio-ulnar synostosis in a boy with Williams-Beuren syndrome]. Acta Chir Orthop Traumatol Cech. 1988 Oct;55(5):473-6.

Charvat KA, Hornstein L, Oestreich AE. Radio-ulnar synostosis in Williams syndrome. A frequently associated anomaly. Pediatr Radiol. 1991;21(7):50810. 
Cherniske EM, Sadler LS, Schwartz D, Carpenter TO, Pober BR. Early puberty in Williams syndrome. Clin Dysmorphol. 1999 Apr;8(2):117-21.

Chiaravalloti G, Rossomando V, Quinti S, Assanta N, Ughi C, Ceccarelli M. [Williams-Beuren syndrome and celiac disease]. Minerva Pediatr. 1995 JanFeb;47(1-2):43-6.

Cho EH, Park BY, Cho JH, Kang YS. Comparing two diagnostic laboratory tests for several microdeletions causing mental retardation syndromes: multiplex ligation-dependent amplification vs fluorescent in situ hybridization. Korean J Lab Med. 2009 Feb;29(1):71-6.

Conway EE, Jr., Noonan J, Marion RW, Steeg CN. Myocardial infarction leading to sudden death in the Williams syndrome: report of three cases. $J$ Pediatr. 1990 Oct;117(4):593-5.

Cortada X, Taysi K, Hartmann AF. Familial Williams syndrome. Clin Genet. 1980 Sep;18(3):173-6.

Curran ME, Atkinson DL, Ewart AK, Morris CA, Leppert MF, Keating MT. The elastin gene is disrupted by a translocation associated with supravalvular aortic stenosis. Cell. 1993 Apr 9;73(1):159-68.

Davies $\mathrm{M}$, Udwin $\mathrm{O}$, Howlin P. Adults with Williams syndrome. Preliminary study of social, emotional and behavioural difficulties. Br J Psychiatry. 1998 Mar;172:273-6.

Del Campo M, Antonell A, Magano LF, Munoz FJ, Flores R, Bayes M, Perez Jurado LA. Hemizygosity at the NCF1 gene in patients with Williams-Beuren syndrome decreases their risk of hypertension. Am J Hum Genet. 2006 Apr;78(4):533-42.

Donnai D, Karmiloff-Smith A. Williams syndrome: from genotype through to the cognitive phenotype. Am J Med Genet. 2000 Summer;97(2):164-71.

Doyle TF, Bellugi U, Korenberg JR, Graham J. "Everybody in the world is my friend" hypersociability in young children with Williams syndrome. Am J Med Genet A. 2004 Jan 30;124A(3):263-73.

Dupont B, Dupont A, Bliddal J, Holst E, Melchior JC, Ottesen OE. Idiopathic hypercalcaemia of infancy. The elfin face syndrome. Dan Med Bull. 1970 Feb;17(2):33-46.

Dutly $F$, Schinzel A. Unequal interchromosomal rearrangements may result in elastin gene deletions causing the Williams-Beuren syndrome. Human Molecular Genetics. 1996 Dec;5(12):1893-8. 
Dutra RL. Análise de marcadores moleculares para o diagnóstico da síndrome de Williams-Beuren. São Paulo: Universidade de São Paulo; 2011.

Dutra RL, Honjo RS, Kulikowski LD, Fonseca FM, Pieri PC, Jehee FS, Bertola DR, Kim CA. Copy number variation in Williams-Beuren syndrome: suitable diagnostic strategy for developing countries. BMC Res Notes. 2012 Jan 9;5(1):13.

Dutra RL, Pieri Pde C, Teixeira AC, Honjo RS, Bertola DR, Kim CA. Detection of deletions at $7 q 11.23$ in Williams-Beuren syndrome by polymorphic markers. Clinics (Sao Paulo). 2011;66(6):959-64.

Edelmann L, Prosnitz A, Pardo S, Bhatt J, Cohen N, Lauriat T, Ouchanov L, Gonzalez PJ, Manghi ER, Bondy P, Esquivel M, Monge S, Delgado MF, Splendore A, Francke U, Burton BK, Mclnnes LA. An atypical deletion of the Williams-Beuren syndrome interval implicates genes associated with defective visuospatial processing and autism. J Med Genet. 2007 Feb;44(2):136-43.

Einfeld SL, Tonge BJ, Florio T. Behavioral and emotional disturbance in individuals with Williams syndrome. Am J Ment Retard. 1997 Jul;102(1):4553.

Ellegren $\mathrm{H}$. Microsatellites: simple sequences with complex evolution. Nat Rev Genet. 2004 Jun;5(6):435-45.

Ewart AK, Morris CA, Atkinson D, Jin W, Sternes K, Spallone P, Stock AD, Leppert M, Keating MT. Hemizygosity at the elastin locus in a developmental disorder, Williams syndrome. Nat Genet. 1993 Sep;5(1):11-6.

Fanconi G, Giardet $P$, Schlesinger B, Butler H, Black JS. Chronischehypercalcamiekombiniertmitosteoskierose,hyper- azotamie, minderwuschs und kogenital missbildungen. Helv Paediatr Acta. 1952;7:31434.

Ferrero GB, Howald C, Micale L, Biamino E, Augello B, Fusco C, Turturo MG, Forzano S, Reymond A, Merla G. An atypical 7q11.23 deletion in a normal IQ Williams-Beuren syndrome patient. Eur J Hum Genet. 2010 Jan;18(1):33-8.

Francke U. Williams-Beuren syndrome: genes and mechanisms. Human Molecular Genetics. 1999;8(10):1947-54.

Gagliardi C, Bonaglia MC, Selicorni A, Borgatti R, Giorda R. Unusual cognitive and behavioural profile in a Williams syndrome patient with atypical 7q11.23 deletion. J Med Genet. 2003 Jul;40(7):526-30. 
Gilbert-Dussardier B, Bonneau D, Gigarel N, Le Merrer M, Bonnet D, Philip N, Serville F, Verloes A, Rossi A, Ayme S, et al. A novel microsatellite DNA marker at locus D7S1870 detects hemizygosity in $75 \%$ of patients with Williams syndrome. Am J Hum Genet. 1995 Feb;56(2):542-4.

Gosch A, Pankau R. Social-emotional and behavioral adjustment in children with Williams-Beuren syndrome. Am J Med Genet. 1994 Dec 1;53(4):335-9.

Gothelf D, Farber N, Raveh E, Apter A, Attias J. Hyperacusis in Williams syndrome: characteristics and associated neuroaudiologic abnormalities. Neurology. 2006 Feb 14;66(3):390-5.

Green T, Avda S, Dotan I, Zarchi O, Basel-Vanagaite L, Zalsman G, Weizman A, Gothelf D. Phenotypic psychiatric characterization of children with Williams syndrome and response of those with ADHD to methylphenidate treatment. Am J Med Genet B Neuropsychiatr Genet. 2012 Jan;159B(1):13-20.

Greenberg F, Lewis RA. The Williams syndrome. Spectrum and significance of ocular features. Ophthalmology. 1988 Dec;95(12):1608-12.

Greer MK, Brown FR, 3rd, Pai GS, Choudry SH, Klein AJ. Cognitive, adaptive, and behavioral characteristics of Williams syndrome. Am J Med Genet. 1997 Sep 19;74(5):521-5.

Gupta P, Tobias JD, Goyal S, Miller MD, Melendez E, Noviski N, De Moor MM, Mehta V. Sudden cardiac death under anesthesia in pediatric patient with Williams syndrome: a case report and review of literature. Ann Card Anaesth. 2010 Jan-Apr;13(1):44-8.

Hallidie-Smith KA, Karas S. Cardiac anomalies in Williams-Beuren syndrome. Arch Dis Child. 1988 Jul;63(7):809-13.

Hirota H, Matsuoka R, Chen XN, Salandanan LS, Lincoln A, Rose FE, Sunahara M, Osawa M, Bellugi U, Korenberg JR. Williams syndrome deficits in visual spatial processing linked to GTF2IRD1 and GTF2I on chromosome 7q11.23. Genet Med. 2003 Jul-Aug;5(4):311-21.

Hirota H, Matsuoka R, Kimura M, Imamura S, Joh-o K, Ando M, Takao A, Momma K. Molecular cytogenetic diagnosis of Williams syndrome. Am J Med Genet. 1996 Aug 23;64(3):473-7.

Hobart HH, Morris CA, Mervis CB, Pani AM, Kistler DJ, Rios CM, Kimberley $\mathrm{KW}$, Gregg RG, Bray-Ward P. Inversion of the Williams syndrome region is a common polymorphism found more frequently in parents of children with Williams syndrome. Am J Med Genet C Semin Med Genet. 2010 May $15 ; 154 \mathrm{C}(2): 220-8$. 
Holmstrom G, Almond G, Temple K, Taylor D, Baraitser M. The iris in Williams syndrome. Arch Dis Child. 1990 Sep;65(9):987-9.

Ino T, Nishimoto K, Iwahara M, Akimoto K, Boku H, Kaneko K, Tokita A, Yabuta K, Tanaka J. Progressive vascular lesions in Williams-Beuren syndrome. Pediatr Cardiol. 1988;9(1):55-8.

Johnson LB, Comeau M, Clarke KD. Hyperacusis in Williams syndrome. J Otolaryngol. 2001 Apr;30(2):90-2.

Jones KL, Smith DW. Smith's recognizable patterns of human malformation: Elsevier Saunders; 2006.

Jones KL, Smith DW. The Williams elfin facies syndrome. A new perspective. J Pediatr. 1975 May;86(5):718-23.

Jones W, Hesselink J, Courchesne E, Duncan T, Matsuda K, Bellugi U. Cerebellar abnormalities in infants and toddlers with Williams syndrome. Dev Med Child Neurol. 2002 Oct;44(10):688-94.

Kaplan P, Kirschner M, Watters G, Costa MT. Contractures in patients with Williams syndrome. Pediatrics. 1989 Nov;84(5):895-9.

Kapp ME, von Noorden GK, Jenkins R. Strabismus in Williams syndrome. Am J Ophthalmol. 1995 Mar;119(3):355-60.

Kececioglu D, Kotthoff S, Vogt J. Williams-Beuren syndrome: a 30-year follow-up of natural and postoperative course. Eur Heart J. 1993 Nov;14(11):1458-64.

Klein AJ, Armstrong BL, Greer MK, Brown FR, 3rd. Hyperacusis and otitis media in individuals with Williams syndrome. J Speech Hear Disord. 1990 May;55(2):339-44.

Kounis NG, Soufras GD, Mazarakis A. The mystery of sudden death in Williams-Beuren syndrome: Cardiomyopathy or Kounis syndrome? Int $\mathrm{J}$ Cardiol. 2011 Nov 10.

Kounis NG, Tsigkas G, Almpanis G, Mazarakis A, Kounis GN. Kounis syndrome--the killer for Williams syndrome? Ann Card Anaesth. 2010 SepDec;13(3):265-6.

Kuijpers GM, De Vroede M, Knol HE, Jansen M. Growth hormone treatment in a child with Williams-Beuren syndrome: a case report. Eur J Pediatr. 1999 Jun;158(6):451-4.

Kumada Y, Yasuda H, Sasaki E, Murakawa S, Mori Y, Hirose H. [Reoperation for diffuse supravalvular aortic stenosis with Williams 
syndrome--extended patch aortoplasty and extra-anatomic bypass from the ascending aorta to the descending aorta in a median sternotomy]. Jpn $J$ Thorac Cardiovasc Surg. 1998 Oct;46(10):1061-4.

Lacolley $P$, Boutouyrie $P$, Glukhova $M$, Daniel Lamaziere JM, Plouin PF, Bruneval P, Vuong P, Corvol P, Laurent S. Disruption of the elastin gene in adult Williams syndrome is accompanied by a paradoxical reduction in arterial stiffness. Clin Sci (Lond). 2002 Jul;103(1):21-9.

Lee WD, Hsu JJ, Huang FC, Chao MC, Chang YL, Huang MH. Ischemic stroke in Williams-Beuren syndrome: a case report. Kaohsiung J Med Sci. 2009 Apr;25(4):212-6.

Levitin DJ. Musical behavior in a neurogenetic developmental disorder: evidence from Williams Syndrome. Ann N Y Acad Sci. 2005 Dec;1060:32534.

Levitin DJ, Cole K, Lincoln A, Bellugi U. Aversion, awareness, and attraction: investigating claims of hyperacusis in the Williams syndrome phenotype. $J$ Child Psychol Psychiatry. 2005 May;46(5):514-23.

Lockwood WW, Chari R, Chi B, Lam WL. Recent advances in array comparative genomic hybridization technologies and their applications in human genetics. Eur J Hum Genet. 2006 Feb;14(2):139-48.

Lowery MC, Morris CA, Ewart A, Brothman LJ, Zhu XL, Leonard CO, Carey JC, Keating M, Brothman AR. Strong correlation of elastin deletions, detected by FISH, with Williams syndrome: evaluation of 235 patients. Am J Hum Genet. 1995 Jul;57(1):49-53.

Martin ND, Snodgrass GJ, Cohen RD. Idiopathic infantile hypercalcaemia--a continuing enigma. Arch Dis Child. 1984 Jul;59(7):605-13.

Martínez-Castilla P, Sotillo M. Singing Abilities in Williams Syndrome. Music Perception. 2008;25(5):449-69.

Martínez-Castilla P, Sotillo M, Campos R. Rhythmic Abilities of Adolescents and Adults with Williams Syndrome. Music Perception: An Interdisciplinary Journal. 2011;29(1):79-91.

Meng X, Lu X, Morris CA, Keating MT. A novel human gene FKBP6 is deleted in Williams syndrome. Genomics. 1998 Sep 1;52(2):130-7.

Mercuri E, Atkinson J, Braddick O, Rutherford MA, Cowan FM, Counsell SJ, Dubowitz LM, Bydder G. Chiari I malformation in asymptomatic young children with Williams syndrome: clinical and MRI study. Eur $J$ Paediatr Neurol. 1997;1(5-6):177-81. 
Merla G, Ucla C, Guipponi M, Reymond A. Identification of additional transcripts in the Williams-Beuren syndrome critical region. Hum Genet. 2002 May;110(5):429-38.

Meyer-Lindenberg A, Mervis CB, Berman KF. Neural mechanisms in Williams syndrome: a unique window to genetic influences on cognition and behaviour. Nat Rev Neurosci. 2006 May;7(5):380-93.

Micale L, Fusco C, Augello B, Napolitano LM, Dermitzakis ET, Meroni G, Merla G, Reymond A. Williams-Beuren syndrome TRIM50 encodes an E3 ubiquitin ligase. Eur J Hum Genet. 2008 Sep;16(9):1038-49.

Miller SA, Dykes DD, Polesky HF. A simple salting out procedure for extracting DNA from human nucleated cells. Nucleic Acids Res. 1988 Feb $11 ; 16(3): 1215$.

Morris CA. The behavioral phenotype of Williams syndrome: A recognizable pattern of neurodevelopment. Am J Med Genet C Semin Med Genet. 2010 Nov 15;154C(4):427-31.

Morris CA. Williams Syndrome. In: Pagon RA, Bird TD, Dolan CR, Stephens K, editors. GeneReviews. Seattle (WA)1993.

Morris CA, Carey JC. Three diagnostic signs in Williams syndrome. Am J Med Genet Suppl. 1990;6:100-1.

Morris CA, Loker J, Ensing G, Stock AD. Supravalvular aortic stenosis cosegregates with a familial $6 ; 7$ translocation which disrupts the elastin gene. Am J Med Genet. 1993 Jul 1;46(6):737-44.

Morris CA, Mervis CB. Williams syndrome and related disorders. Annu Rev Genomics Hum Genet. 2000;1:461-84.

Morris CA, Mervis CB, Hobart HH, Gregg RG, Bertrand J, Ensing GJ, Sommer A, Moore CA, Hopkin RJ, Spallone PA, Keating MT, Osborne L, Kimberley KW, Stock AD. GTF2l hemizygosity implicated in mental retardation in Williams syndrome: genotype-phenotype analysis of five families with deletions in the Williams syndrome region. Am J Med Genet $A$. 2003 Nov 15;123A(1):45-59.

Morris CA, Pani AM, Mervis CB, Rios CM, Kistler DJ, Gregg RG. Alpha 1 antitrypsin deficiency alleles are associated with joint dislocation and scoliosis in Williams syndrome. Am J Med Genet C Semin Med Genet. 2010 May 15;154C(2):299-306.

Nickerson E, Greenberg F, Keating MT, McCaskill C, Shaffer LG. Deletions of the elastin gene at $7 q 11.23$ occur in approximately $90 \%$ of patients with Williams syndrome. Am J Hum Genet. 1995 May;56(5):1156-61. 
Nigam A, Samuel PR. Hyperacusis and Williams syndrome. J Laryngol Otol. 1994 Jun;108(6):494-6.

Nogueira RJ, Zimmerman LF, Moreno YM, Comparini CR, Viana DV, Vieira TA, Steiner CE, Gil-da-Silva-Lopes VL. Anthropometric and body-mass composition suggests an intrinsic feature in Williams-Beuren syndrome. Rev Assoc Med Bras. 2011 Dec;57(6):681-5.

Nunes MM. Avaliação do funcionamento cognitivo de pacientes com Síndrome de Williams-Beuren. São Paulo: Universidade de São Paulo; 2010.

Nunes MM, Honjo RS, Dutra RL, Amaral VAAS, Oh HK, Bertola DR, Albano LMJ, Assumpção Júnior $F$, Kim CA. High frequency of autistic traits in Williams- Beuren patients. Pedlatrla (São Paulo). 2011;33(2):81-8.

Osborne LR, Joseph-George AM, Scherer SW. Williams-Beuren syndrome diagnosis using fluorescence in situ hybridization. Methods Mol Med. 2006;126:113-28.

Osborne LR, Li M, Pober B, Chitayat D, Bodurtha J, Mandel A, Costa T, Grebe T, Cox S, Tsui LC, Scherer SW. A 1.5 million-base pair inversion polymorphism in families with Williams-Beuren syndrome. Nat Genet. 2001 Nov;29(3):321-5.

Ounap K, Laidre P, Bartsch O, Rein R, Lipping-Sitska M. Familial WilliamsBeuren syndrome. Am J Med Genet. 1998 Dec 28;80(5):491-3.

Pankau R, Gosch A, Wessel A. Radioulnar synostosis in Williams-Beuren syndrome: a component manifestation. Am J Med Genet. 1993 Mar $15 ; 45(6): 783$.

Pankau R, Partsch CJ, Gosch A, Oppermann HC, Wessel A. Statural growth in Williams-Beuren syndrome. Eur J Pediatr. 1992 Oct;151(10):751-5.

Pankau R, Partsch CJ, Winter M, Gosch A, Wessel A. Incidence and spectrum of renal abnormalities in Williams-Beuren syndrome. Am J Med Genet. 1996 May 3;63(1):301-4.

Pankau R, Siebert R, Kautza M, Schneppenheim R, Gosch A, Wessel A, Partsch CJ. Familial Williams-Beuren syndrome showing varying clinical expression. Am J Med Genet. 2001 Feb 1;98(4):324-9.

Partsch CJ, Dreyer G, Gosch A, Winter M, Schneppenheim R, Wessel A, Pankau R. Longitudinal evaluation of growth, puberty, and bone maturation in children with Williams syndrome. J Pediatr. 1999 Jan;134(1):82-9. 
Perez Jurado LA, Peoples R, Kaplan P, Hamel BC, Francke U. Molecular definition of the chromosome 7 deletion in Williams syndrome and parent-oforigin effects on growth. Am J Hum Genet. 1996 Oct;59(4):781-92.

Pleatman SI, Dunbar JS. Colon diverticula in Williams elfin-facies syndrome. Radiology. 1980 Dec;137(3):869-70.

Pober BR. Williams-Beuren syndrome. N Engl J Med. 2010 Jan 21;362(3):239-52.

Pober BR, Filiano JJ. Association of Chiari I malformation and Williams syndrome. Pediatr Neurol. 1995 Jan;12(1):84-8.

Pober BR, Lacro RV, Rice C, Mandell V, Teele RL. Renal findings in 40 individuals with Williams syndrome. Am J Med Genet. 1993 May 15;46(3):271-4.

Pober BR, Morris CA. Diagnosis and management of medical problems in adults with Williams-Beuren syndrome. Am J Med Genet C Semin Med Genet. 2007 Aug 15;145C(3):280-90.

Pober BR, Wang E, Caprio S, Petersen KF, Brandt C, Stanley T, Osborne LR, Dzuria J, Gulanski B. High prevalence of diabetes and pre-diabetes in adults with Williams syndrome. Am J Med Genet C Semin Med Genet. 2010 May 15;154C(2):291-8.

Power TJ, Blum NJ, Jones SM, Kaplan PE. Brief report: response to methylphenidate in two children with Williams syndrome. $J$ Autism Dev Disord. 1997 Feb;27(1):79-87.

Putman CM, Chaloupka JC, Eklund JE, Fulbright RK. Multifocal intracranial occlusive vasculopathy resulting in stroke: an unusual manifestation of Williams syndrome. AJNR Am J Neuroradiol. 1995 Aug;16(7):1536-8.

Rein AJ, Preminger TJ, Perry SB, Lock JE, Sanders SP. Generalized arteriopathy in Williams syndrome: an intravascular ultrasound study. J Am Coll Cardiol. 1993 Jun;21(7):1727-30.

Reiss AL, Eliez S, Schmitt JE, Straus E, Lai Z, Jones W, Bellugi U. IV. Neuroanatomy of Williams syndrome: a high-resolution MRI study. J Cogn Neurosci. 2000;12 Suppl 1:65-73.

Sadler LS, Gingell R, Martin DJ. Carotid ultrasound examination in Williams syndrome. J Pediatr. 1998 Feb;132(2):354-6.

Sadler LS, Robinson LK, Verdaasdonk KR, Gingell R. The Williams syndrome: evidence for possible autosomal dominant inheritance. Am J Med Genet. 1993 Sep 15;47(4):468-70. 
Sammour ZM, Gomes CM, Duarte RJ, Trigo-Rocha FE, Srougi M. Voiding dysfunction and the Williams-Beuren syndrome: a clinical and urodynamic investigation. J Urol. 2006 Apr;175(4):1472-6.

Sbruzzi IC. Estudo de marcadores polimórficos da região 7q11.23 para o diagnóstico da Síndrome de Williams-Beuren. São Paulo: Universidade de São Paulo; 2006.

Scherer SW, Gripp KW, Lucena J, Nicholson L, Bonnefont JP, Perez-Jurado LA, Osborne LR. Observation of a parental inversion variant in a rare Williams-Beuren syndrome family with two affected children. Hum Genet. 2005 Aug;117(4):383-8.

Schlesinger BE, Butler NR, Black JA. Severe type of infantile hypercalcaemia. Br Med J. 1956 Jan 21;1(4959):127-34.

Schouten JP, McElgunn CJ, Waaijer R, Zwijnenburg D, Diepvens F, Pals G. Relative quantification of 40 nucleic acid sequences by multiplex ligationdependent probe amplification. Nucleic Acids Res. 2002 Jun 15;30(12):e57.

Schubert $\mathrm{C}$. The genomic basis of the Williams-Beuren syndrome. Cell Mol Life Sci. 2009 Apr;66(7):1178-97.

Schulman SL, Zderic S, Kaplan P. Increased prevalence of urinary symptoms and voiding dysfunction in Williams syndrome. J Pediatr. 1996 Sep;129(3):466-9.

Selicorni A, Fratoni A, Pavesi MA, Bottigelli M, Arnaboldi E, Milani D. Thyroid anomalies in Williams syndrome: investigation of 95 patients. Am J Med Genet A. 2006 May 15;140(10):1098-101.

Shah PS, Murthy P, Skidmore D, Shaffer LG, Bejjani BA, Chitayat D. Williams syndrome in a preterm infant with phenotype of Alagille syndrome. Am J Med Genet A. 2008 Sep 15;146A(18):2407-11.

Stankiewicz P, Beaudet AL. Use of array CGH in the evaluation of dysmorphology, malformations, developmental delay, and idiopathic mental retardation. Curr Opin Genet Dev. 2007 Jun;17(3):182-92.

Stoermer J, Olbing H, Hentrich F, Even K, Galal O, Bachmann J. [Syndrome of supravalvular aortic stenosis (Williams-Beuren syndrome) in association with changes in the kidney and efferent urinary tract]. Monatsschrift Kinderheilkunde : Organ der Deutschen Gesellschaft fur Kinderheilkunde. 1984 Feb;132(2):110-2.

Stromme P, Bjornstad PG, Ramstad K. Prevalence estimation of Williams syndrome. J Child Neurol. 2002 Apr;17(4):269-71. 
Suarez-Mier MP, Morentin B. Supravalvular aortic stenosis, Williams syndrome and sudden death. A case report. Forensic Sci Int. 1999 Nov 22;106(1):45-53.

Sugayama SM, de Sá LCF, Abe KT, Leone C, Chauffaille MLLF, Kim CA. Anormalidades oculares em 20 pacientes com síndrome de Williams-Beuren. Pediatria (São Paulo) 2002;24(3/4):98-104.

Sugayama SM, Koch VH, Furusawa EA, Leone C, Kim CA. Renal and urinary findings in 20 patients with Williams-Beuren syndrome diagnosed by fluorescence in situ hybridization (FISH). Rev Hosp Clin Fac Med Sao Paulo. 2004 Oct;59(5):266-72.

Sugayama SMM. Estudo genético-clínico e citogenética molecular pela técnica da hibridização in situ por fluorescência (FISH) em pacientes com síndrome de Williams-Beuren. São Paulo: Universidade de São Paulo; 2001.

Tassabehji M. Williams-Beuren syndrome: a challenge for genotypephenotype correlations. Human Molecular Genetics. 2003 Oct 15;12 Spec No 2:R229-37.

Tobias-Machado M, Marinelli CM, Sakuramoto PK, Spinola RT, Borrelli Junior M, Freire Gde C, Borrelli M. [Neuro-urological findings in Williams syndrome: report of a case]. Arq Neuropsiquiatr. 1998 Sep;56(3B):683-7.

Tomaiuolo F, Di Paola M, Caravale B, Vicari S, Petrides M, Caltagirone C. Morphology and morphometry of the corpus callosum in Williams syndrome: a T1-weighted MRI study. Neuroreport. 2002 Dec 3;13(17):2281-4.

Tordjman S, Anderson GM, Botbol M, Toutain A, Sarda P, Carlier M, Saugier-Veber P, Baumann C, Cohen D, Lagneaux C, Tabet AC, Verloes A. Autistic disorder in patients with williams-beuren syndrome: a reconsideration of the williams-beuren syndrome phenotype. PLoS One. 2012;7(3):e30778.

Udwin O. A survey of adults with Williams syndrome and idiopathic infantile hypercalcaemia. Dev Med Child Neurol. 1990 Feb;32(2):129-41.

Udwin O, Yule W. A cognitive and behavioural phenotype in Williams syndrome. J Clin Exp Neuropsychol. 1991 Mar;13(2):232-44.

Unuma K, Harada K, Furutani M, Furutani Y, Nakajima M, Nakanishi T, Matsuoka R, Yoshida K. Multiple stenotic arteriopathy in a 72-year-old female with Williams syndrome. J Clin Pathol. 2011 Apr;64(4):368-70.

Urban Z, Helms C, Fekete G, Csiszar K, Bonnet D, Munnich A, Donis-Keller $\mathrm{H}$, Boyd CD. 7q11.23 deletions in Williams syndrome arise as a 
consequence of unequal meiotic crossover. Am J Hum Genet. 1996 Oct;59(4):958-62.

van Hagen JM, Eussen HJ, van Schooten R, van Der Geest JN, Lagers-van Haselen GC, Wouters CH, De Zeeuw Cl, Gille JJ. Comparing two diagnostic laboratory tests for Williams syndrome: fluorescent in situ hybridization versus multiplex ligation-dependent probe amplification. Genet Test. 2007 Fall;11(3):321-7.

Vernant P, Corone P, Rossignol AM, Bielman C. [120 cases of the Williams and Beuren syndrome]. Arch Mal Coeur Vaiss. 1980 Jun;73(6):661-6.

Weber JL. Human DNA polymorphisms and methods of analysis. Curr Opin Biotechnol. 1990 Dec;1(2):166-71.

Wessel A, Gravenhorst V, Buchhorn R, Gosch A, Partsch CJ, Pankau R. Risk of sudden death in the Williams-Beuren syndrome. Am J Med Genet A. 2004 Jun 15;127A(3):234-7.

Wessel A, Motz R, Pankau R, Bursch JH. [Arterial hypertension and blood pressure profile in patients with Williams-Beuren syndrome]. Z Kardiol. 1997 Apr;86(4):251-7.

Williams JC, Barratt-Boyes BG, Lowe JB. Supravalvular aortic stenosis. Circulation. 1961 Dec;24:1311-8.

Williams RL, Azouz EM. Aortic anomalies in an adolescent with the Williams' elfin facies syndrome. Pediatr Radiol. 1984;14(2):122-4.

Wollack JB, Kaifer M, LaMonte MP, Rothman M. Stroke in Williams syndrome. Stroke. 1996 Jan;27(1):143-6.

Wu YQ, Sutton VR, Nickerson E, Lupski JR, Potocki L, Korenberg JR, Greenberg F, Tassabehji M, Shaffer LG. Delineation of the common critical region in Williams syndrome and clinical correlation of growth, heart defects, ethnicity, and parental origin. Am J Med Genet. 1998 Jun 16;78(1):82-9.

Zalzstein E, Moes CA, Musewe NN, Freedom RM. Spectrum of cardiovascular anomalies in Williams-Beuren syndrome. Pediatr Cardiol. 1991 Oct;12(4):219-23. 